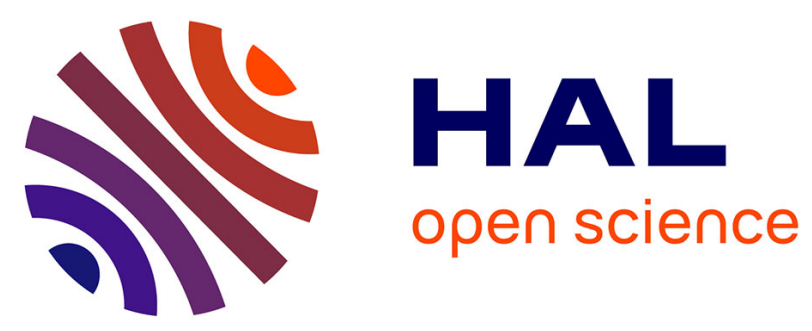

\title{
Lyme borreliosis and other tick-borne diseases. Guidelines from the French Scientific Societies (I) prevention, epidemiology, diagnosis
}

J Figoni, C Chirouze, Y Hansmann, C Lemogne, V Hentgen, A Saunier, K Bouiller, J F Gehanno, C Rabaud, S Perrot, et al.

\section{To cite this version:}

J Figoni, C Chirouze, Y Hansmann, C Lemogne, V Hentgen, et al.. Lyme borreliosis and other tickborne diseases. Guidelines from the French Scientific Societies (I) prevention, epidemiology, diagnosis. Médecine et Maladies Infectieuses, 2019, 49 (5), pp.318-334. 10.1016/j.medmal.2019.04.381 . hal02153620

HAL Id: hal-02153620

https://hal-univ-rennes1.archives-ouvertes.fr/hal-02153620

Submitted on 18 Nov 2019

HAL is a multi-disciplinary open access archive for the deposit and dissemination of scientific research documents, whether they are published or not. The documents may come from teaching and research institutions in France or abroad, or from public or private research centers.
L'archive ouverte pluridisciplinaire HAL, est destinée au dépôt et à la diffusion de documents scientifiques de niveau recherche, publiés ou non, émanant des établissements d'enseignement et de recherche français ou étrangers, des laboratoires publics ou privés. 
Borréliose de Lyme et autres maladies vectorielles à tiques. Recommandations françaises des sociétés savantes (Argumentaire I): prévention, épidémiologie, circonstances du diagnostic.

Lyme borreliosis and other tick-borne diseases: French guidelines from scientific societies (I): prevention, epidemiology, circumstances of diagnosis.

J. Figoni, ${ }^{1,2}$ C. Chirouze, ${ }^{3}$ Y. Hansmann, ${ }^{4}$ C. Lemogne,${ }^{5}$ V. Hentgen, ${ }^{6}$ A. Saunier, ${ }^{7}$ K. Bouiller, ${ }^{3}$ J.-F. Gehanno, ${ }^{8}$ C. Rabaud,${ }^{9}$ S. Perrot,${ }^{10}$ E. Caumes,${ }^{11}$ C. Eldin, ${ }^{12}$ T. de Broucker, ${ }^{13}$ B. Jaulhac, ${ }^{14}$ F. Roblot, ${ }^{15}$ J. Toubiana, ${ }^{16}$ F. Sellal,,${ }^{17}$ F. Vuillemet, ${ }^{17}$ C. Sordet,${ }^{18}$ B. Fantin, ${ }^{19}$ G. Lina, ${ }^{20}$ X. Gocko,${ }^{21}$ M. Dieudonné, ${ }^{22}$ O. Picone, ${ }^{23}$ B. Bodaghi, ${ }^{23}$ J.-P. Gangneux, ${ }^{24}$ B. Degeilh, ${ }^{24}$ H. Partouche, ${ }^{25}$ C. Lenormand, ${ }^{26}$ A. Sotto, ${ }^{27}$ A. Raffetin, ${ }^{28}$ J.-J. Monsuez, ${ }^{29}$ C. Michel,${ }^{30}$ N. Boulanger, ${ }^{14}$ P. Cathebras, ${ }^{31}$ P. Tattevin ${ }^{32 *}$

${ }^{1}$ Santé Publique France, St Maurice, France

${ }^{2}$ Maladies Infectieuses et Tropicales, Hôpital Avicenne, Bobigny, France

${ }^{3}$ Maladies Infectieuses et Tropicales, Centre Hospitalo-Universitaire, UMR CNRS 6249 Université Bourgogne Franche Comté, Besançon, France

${ }^{4}$ Maladies Infectieuses et Tropicales, Centre Hospitalo-Universitaire, Strasbourg, France

${ }^{5}$ Psychiatrie, Hôpital européen Georges-Pompidou, AP-HP.5; Inserm U1266; Université Paris Descartes, Paris, France

${ }^{6}$ Pédiatrie, Centre Hospitalier, Versailles, France

${ }^{7}$ Médecine Interne et Maladies Infectieuses, Centre Hospitalier, Périgueux, France

${ }^{8}$ Médecine du Travail, Centre Hospitalo-Universitaire, Rouen, France

${ }^{9}$ Maladies Infectieuses et Tropicales, Centre Hospitalo-Universitaire, Nancy, France

${ }^{10}$ Centre d'Etude et de Traitement de la Douleur, Hôpital Cochin, Paris, France

${ }^{11}$ Maladies Infectieuses et Tropicales, Hôpital La Pitié-Salpêtrière, Paris, France

${ }^{12}$ Maladies Infectieuses et Tropicales, IHU Méditerranée Infection, Centre Hospitalo-Universitaire Timone, Marseille, France

${ }^{13}$ Neurologie, Hôpital Delafontaine, Saint-Denis, France 
${ }^{14}$ Laboratoire de Bactériologie et CNR des Borrelia, Faculté de Médecine et Centre Hospitalo-Universitaire, Strasbourg, France

${ }^{15}$ Maladies Infectieuses et Tropicales, Centre Hospitalo-Universitaire, INSERM U1070, Poitiers, France

${ }^{16}$ Service de Pédiatrie Générale et Maladies Infectieuses, Hôpital Necker - Enfants Malades, APHP, Paris, France

${ }^{17}$ Département de Neurologie, Hôpitaux Civil, Colmar, France

${ }^{18}$ Rhumatologie, Centre Hospitalo-Universitaire, Strasbourg, France

${ }^{19}$ Médecine interne, Hôpital Beaujon, Université Paris Diderot, INSERM UMR 1137 IAME,

Clichy, France

${ }^{20}$ Microbiologie, Centre Hospitalo-Universitaire, Lyon, France

${ }^{21}$ Département de Médecine Générale, Faculté de Médecine, Saint-Etienne, France

${ }^{22}$ Centre Max Weber, CNRS, Université Lyon 2, Lyon, France

${ }^{23}$ Ophtalmologie, Hôpital La Pitié-Salpêtrière, Paris, France

${ }^{24}$ Laboratoire de Parasitologie-Mycologie, UMR_S 1085 Irset Université Rennes1-Inserm-EHESP, Centre Hospitalo-Universitaire, Rennes, France

${ }^{25}$ Cabinet de médecine générale, Saint-Ouen. Département de médecine Générale. Faculté de Médecine. Université Paris Descartes, Paris, France

${ }^{26}$ Dermatologie, Hôpitaux Universitaires de Strasbourg et Faculté de Médecine, Université de Strasbourg, France

${ }^{27}$ Maladies Infectieuses et Tropicales, Centre Hospitalo-Universitaire, Nîmes, France

${ }^{28}$ Maladies Infectieuses et Tropicales, Centre Hospitalier Intercommunal, Villeneuve-St-Georges, France

${ }^{29}$ Cardiologie, Hôpital René Muret, Sevran, France

${ }^{30}$ Médecine Générale, Strasbourg, France

${ }^{31}$ Médecine Interne, Hôpital Nord, Centre Hospitalo-Universitaire, Saint-Etienne, France

${ }^{32}$ Maladies Infectieuses et Réanimation Médicale, Hôpital Pontchaillou, Centre Hospitalo-Universitaire, Rennes, France 


\section{Validations Sociétés Savantes:}

- Société Française de Dermatologie (SFD)

- Société Française de Rhumatologie (SFR)

- Société Française de Neurologie (SFN)

- Fédération Française de Neurologie (FFN)

- Société Française de Neurologie (SFN)

- Collège National des Généralistes Enseignants (CNGE)

- Collège de la Médecine Générale (CMG)

- Société Nationale Française de Médecine Interne (SNFMI)

- Société Française de Microbiologie (SFM)

- Collège National pour la Qualité des Soins en Psychiatrie (CNQSP)

- Association Française de Psychiatrie Biologique et de Neuropsychopharmacologie (AFPBN)

- Société de Psychologie Médicale et de Psychiatrie de Liaison de Langue Française (SPMPLLF)

- Société Française de Médecine du Travail (SFMT)

- Société Française de Cardiologie (SFC)

- Société Française de Pédiatrie (SPD)

- Groupe de Pathologies Infectieuses Pédiatriques (GPIP)

- Société Française de Rhumatologie et Médecine Interne Pédiatrique (SOFREMIP)

- Société Française d'Ophtalmologie (SFO)

- Collège National des Professionnels en Psychiatrie (CNPP)

- Société Française de Mycologie Médicale (SFMM)

- Société Française de Parasitologie (SFP)

- Collège des universitaires de Maladies Infectieuses et Tropicales (CMIT)

- Collège National des Obstétriciens et Gynécologues (CNOG)

- Société Française d'Etude et de Traitement de la Douleur (SFETD) 
- Société de Pathologie Infectieuse de Langue Française (SPILF)

* Auteur correspondant: Service des Maladies Infectieuses et Réanimation Médicale, CHU Pontchaillou, 35033 Rennes cedex, France. e-mail: pierre.tattevin@chu-rennes.fr 


\begin{abstract}
La borréliose de Lyme est transmise en France par la tique Ixodes ricinus, présente sur tout le territoire métropolitain. En l'absence de vaccin, la prévention primaire repose sur les mesures de protection mécanique (vêtements couvrants), éventuellement complétées par la protection chimique (répulsifs). La prévention secondaire repose sur le repérage précoce des tiques après exposition et leur extraction mécanique. Il n'existe aucune situation justifiant une antibioprophylaxie post-piqûre de tiques en France. L'incidence de la borréliose de Lyme, estimée à travers le réseau Sentinelles et les codages des séjours hospitaliers, a été stable en France entre 2009 et 2017, avec une moyenne de 53 cas/100 000 habitants/an, à l'origine d'1,1 hospitalisation/100 000 habitants/an. Les autres maladies transmises par les tiques sont beaucoup plus rares en France: encéphalite à tiques (environ 20 cas/an), rickettsioses du groupe 'boutonneux' (fièvre boutonneuse méditerranéenne, environ 10 cas/an), tularémie (50 à 100 cas/an, dont $20 \%$ transmis par des tiques), anaplasmose granulocytaire humaine ( $<10$ cas/an) et babésiose ( $<5$ cas/an). Les principaux points d'appel pour une borréliose de Lyme sont les manifestations cutanées (érythème migrant principalement, beaucoup plus rarement lymphocytome borrélien et acrodermatite chronique atrophiante), neurologiques ( $<15 \%$ des cas, essentiellement méningoradiculite et atteinte d'un ou plusieurs nerf(s) crânien(s), surtout le nerf facial) et articulaires (principalement monoarthrite récidivante du genou). Les manifestations cardiaques et ophtalmologiques sont exceptionnelles.
\end{abstract}

Mots-clés: borréliose de Lyme; prévention; tiques; Ixodes ; France ; épidemiologie ; érythème migrant ; arthrite ; neuroborréliose 


\begin{abstract}
Lyme borreliosis is transmitted en France by the tick Ixodes ricinus, endemic in metropolitan France. In the absence of vaccine licensed for use in humans, primary prevention mostly relies on mechanical protection (clothes covering most parts of the body), that may be completed by chemical protection (repulsives). Secondary prevention relies on early detection of ticks after exposure, and mechanical extraction. There is currently no situation in France when prophylactic antibiotics would be recommended.

The incidence of Lyme borreliosis in France, estimated through a network of general practitioners (réseau Sentinelles), and nationwide coding system for hospital stays, has not significantly changed between 2009 and 2017, with a mean incidence estimated at 53 cases/100 000 inhabitants/year, leading to 1.1 hospital admission/100 000 inhabitants/year. Other tick-borne diseases are much more seldom in France: tick-borne encephalitis (around 20 cases/year), spotted-fever rickettsiosis (primarily mediterranean spotted fever, around 10 cases/an), tularemia (50-100 cases/year, of which 20\% are transmitted by ticks), human granulocytic anaplasmosis ( $<10$ cases/year), and babesiosis ( $<5$ cases/year).

The main circumstances of diagnosis for Lyme borreliosis are cutaneous manifestations (primarily erythema migrans, much more rarely borrelial lymphocytoma and atrophic chronic acrodermatitis), neurological ( $<15 \%$ of cases, mostly meningoradiculitis and cranial nerve palsy, especially facial nerve) and rheumatologic (mostly knee monoarthritis, chronic or with recurrences). Cardiac and ophtalmologic manifestations are very rarely encountered.
\end{abstract}

Keywords: Lyme borreliosis; prevention; ticks; Ixodes ; France ; epidemiology ; erythema migrans ; arthritis ; neuroborreliosis 


\section{Prévention}

\section{1 Écologie des tiques}

Les tiques sont des acariens, regroupés en deux familles: les tiques dures, ou Ixodidae, et les tiques molles, ou Argasidae (Tableau 1). Les piqûres de tiques molles ont lieu le plus souvent la nuit et ne durent que quelques minutes. Elles ne transmettent pas d'agents infectieux à l'homme, mais peuvent être responsables de chocs anaphylactiques [1]. Parmi les tiques dures, Ixodes, Dermacentor et Rhipicephalus sont les plus incriminées pour l'Homme. Ixodes ricinus et Dermacentor sont présents sur tout le territoire français métropolitain, tandis que Rhipicephalus est moins répandu (https://ecdc.europa.eu/en/diseasevectors/surveillance-and-disease-data/tick-maps).

Les Ixodes montent sur la végétation (jusqu'à 1,50 m du sol) pour trouver un hôte et redescendent se réhydrater dans le sol. Elles sont très sensibles à la dessiccation. Elles piquent en journée et le repas sanguin dure plusieurs jours [2]. Les tiques Dermacentor piquent les chiens et les ongulés (ovins, etc.), mais aussi l'homme, le plus souvent au niveau du cuir chevelu. Rhipicephalus sanguineus prédomine dans les régions à climat chaud et à hiver doux [2].

En 2016, un quart de la population métropolitaine a déclaré avoir été piqué par une tique au cours de sa vie. Toute personne peut être exposée lors d'activités dans la nature (forêt, campagne), dans les parcs urbains, ou les jardins privatifs où la végétation est abondante. Les tiques non fixées présentes sur les chiens et chats domestiques au retour d'une sortie dans la nature représentent également un risque pour l'homme [3]. Les tiques Dermacentor adulte et Ixodes sont présentes dans la végétation, car les nymphes et larves vivent dans les terriers. La tique Rhipicephalus, endophile, se rencontre dans les niches car inféodée aux chiens, dans les murs extérieurs, voire à l'intérieur des habitations. Pour les DOM-TOM, peu de piqûres de tiques sont rapportées.

\subsection{Protection personnelle anti-vectorielle}

\subsubsection{Prévention primaire}

Ixodes, de loin la plus abondante dans notre environnement, est active entre mars et novembre en climat continental, et toute l'année en zone océanique, tout comme Dermacentor. Rhipicephalus est plus agressive vis-à-vis de l'homme en climat chaud [4].

Protection mécanique. La meilleure prévention est le port de vêtements couvrants: pantalon long mis dans les chaussettes - voire guêtres - et chemise à manche longue, de préférence de couleur claire pour mieux repérer les tiques (grade $\boldsymbol{A E}$ ) [5]. Pour les jeunes enfants, une protection de la tête par un chapeau est souhaitable car, en raison de leur taille et activités, ils sont plus à risque d'être piqués par les tiques à l'affût sur les hautes herbes (grade $\boldsymbol{A E}$ ).

Protection chimique. Les répulsifs perturbent le système olfactif des tiques, empêchant le repérage de l'hôte, mais ne les tuent pas [6]. Ils ne sont qu'un complément à la protection mécanique pour des expositions occasionnelles, du fait de l'absence de données de tolérance pour les expositions répétées sur le long terme (grade B). Chez les femmes enceintes et les enfants de moins de 24 mois, les répulsifs ne sont 
pas recommandés en l'absence d'évaluation du bénéfice/risque (grade $\boldsymbol{A} \boldsymbol{E}$ ). Les molécules répulsives recommandées sont les suivantes:_DEET (seule molécule ayant une autorisation de mise sur le marché), IR35/35, KBR 3023, PMDRBO (principe actif synthétique de l'eucalyptus citronné). Plusieurs règles sont à respecter: appliquer sur peau découverte (inutile sous les vêtements), respecter l'âge indiqué dans la notice et le rythme des applications, ne pas appliquer en même temps qu'une protection antisolaire (grade B) [7].

Les huiles essentielles, extraites de plantes (lavande, citronnelle, etc.), volatiles, ne sont pas recommandées en raison de leur durée répulsive brève ( $<1$ h) (grade $\boldsymbol{A} \boldsymbol{E})$. Certains composés peuvent être photosensibilisants, irritants ou cancérogènes. Les bracelets insecticides n'ont pas fait preuve de leur efficacité et ne sont pas recommandés (grade $\boldsymbol{A} \boldsymbol{E}$ ). Il est possible d'imprégner les vêtements avec des répulsifs à base de pyréthrine (grade $\boldsymbol{A E}$ ). Toutefois, leur tolérance en cas d'utilisation prolongée n'a pas été évaluée et $0,5 \%$ de la dose appliquée sur la peau est absorbée [8].

Protection vaccinale. Il n'existe pas de vaccin contre la borréliose de Lyme pour l'Homme. Le vaccin contre l'encéphalite à tiques est recommandé avant un séjour en zone rurale ou boisée dans les régions d'endémie, $\quad \mathrm{du} \quad$ printemps à l'automne (invs.santepubliquefrance.fr/content/.../62/file/Recommandations_voyageurs_2018.pdf).

\subsubsection{Prévention secondaire}

La prévention secondaire regroupe les mesures recommandées après exposition aux piqûres de tique. Ces mesures s'appliquent même si les mesures de prévention primaire ont été observées (grade $\boldsymbol{A E}$ ).

Au retour de zones à risque, l'inspection corporelle minutieuse est recommandée (grade AE) [9], tout particulièrement les zones chaudes et humides (creux poplités, inguinaux et axillaires, plis du coude, ombilic), le cuir chevelu et les oreilles, surtout chez les jeunes enfants. La piqûre de Dermacentor est souvent localisée à la base du cuir chevelu, celle de Rhipicephalus sur les membres inférieurs et dans les plis. La douche peut être l'occasion de compléter l'inspection corporelle. La taille des tiques est variable selon la stase (figure 1). La tique grossissant avec son repas sanguin, il est recommandé de répéter l'inspection le lendemain de l'exposition (grade $\boldsymbol{A E}$ ).

Si une tique est détectée, il est recommandé de (grade $\boldsymbol{A E}$ ) [9]:

- pratiquer une extraction mécanique avec un crochet à tique ou une pince fine, le plus rapidement possible: les virus sont transmis dès le début du repas sanguin et les bactéries ou parasites dans un délai de $24 \mathrm{~h}$. Si les pièces piqueuses n'ont pu être retirées, elles peuvent être laissées en place dans la peau sans risque car les glandes salivaires qui contiennent les agents infectieux sont dans le corps de la tique qui a été retirée. La persistance des pièces piqueuses entraînera la formation d'un granulome qui disparaîtra spontanément. Il est déconseillé d'extraire la tique avec les doigts ou d'utiliser des substances telles qu'éther, huile, vernis. Autour de la piqûre, une zone inflammatoire due à la réaction à la salive de tique peut être observée (Figure 2), non extensive, contrairement à l'érythème migrant (EM). Cette réaction disparaît en 48/72 h.

- désinfecter la peau au point de piqûre avec un antiseptique, après retrait de la tique.

- se laver les mains avec du savon. 
- réaliser une photographie de la tique et noter la date et le lieu de piqûre: cette photographie pourra être montrée à un médecin ou pharmacien pour identification.

- surveiller la zone au cours des 4 semaines qui suivent afin de détecter un EM qui signerait une borréliose de Lyme [10], ou une escarre d'inoculation. Il convient alors de prendre un avis médical en précisant la piqûre récente.

Après piqûre de tique, le risque de borréliose de Lyme est $<5 \%$, même en zone de forte endémie et après fixation prolongée de la tique [11]. Par conséquent, après piqûre de tique en France:

- il n'est pas recommandé de réaliser un sérodiagnostic [12] ou un autotest (http://slbc.fr/wpcontent/uploads/2018/03/18-01-Rapport-autotests-TROD-VF8-académie-de-pharmacie.pdf) (grade A),

- il n'est pas recommandé de tester la tique extraite pour rechercher des agents infectieux (grade A),

- il n'est pas recommandé d'instaurer une antibiothérapie, quel que soit l'âge de la personne piquée, le temps d'attachement et la stase de la tique retirée (grade $\boldsymbol{B})$.

\subsection{Prévention collective}

Les maladies transmises par les tiques sont des zoonoses. L'Homme est un hôte accidentel qui se fait piquer lorsqu'il se rend dans l'écosystème des tiques [13]. La prévention collective comprend les mesures visant à prévenir les piqûres de tiques en contrôlant leur écosystème autour des zones d'activités humaines [9].

\subsubsection{Contrôle de l'habitat des tiques.}

Il est possible de limiter les populations de tiques en coupant l'herbe dans les espaces verts et autour des habitations et par l'entretien des écosystèmes forestiers, en évitant des tas de branches et de bois mort où se trouvent les rongeurs, réservoirs pour les tiques et certains pathogènes. L'épandage d'acaricides pratiqué aux États-Unis n'est pas utilisé en France pour des raisons environnementales.

\subsubsection{Protection contre la faune sauvage.}

Les cervidés sont des hôtes privilégiés pour les tiques Ixodes adultes qui maintiennent les populations de tiques dans les écosystèmes [14]. La présence de clôtures efficaces contre la faune sauvage diminue la présence de tiques dans les zones d'activités humaines.

\subsubsection{Prévention des piqûres de tique à partir des animaux domestiques}

Seules les tiques non fixées peuvent passer de l'animal domestique à l'Homme [3]. Il est recommandé de peigner/brosser le pelage de l'animal après une sortie dans la nature ou d'utiliser des traitements vétérinaires acaricides (grade $\boldsymbol{A E}$ ). Les tiques retirées doivent être éliminées. 
Cette épidémiologie est liée à l'écologie des tiques et leur distribution géographique. Il existe en France un dispositif de surveillance de la borréliose de Lyme impliquant différents acteurs. La surveillance des autres maladies transmises par les tiques repose sur les Centres Nationaux de Référence (CNR).

\subsection{Borréliose de Lyme}

Les bactéries responsables de la borréliose de Lyme en Europe sont Borrelia burgdorferi sensu stricto, Borrelia garinii et Borrelia afzelii. Aux Etats-Unis, Borrelia burgdorferi sensu stricto est très majoritaire. En France, la surveillance repose sur:

- Le Réseau Sentinelles (INSERM/Sorbonne université, Santé publique France), également impliqué dans la surveillance d'autres maladies, basé sur le volontariat de médecins généralistes. Ces derniers déclarent les cas de borréliose de Lyme diagnostiquent: https://www.sentiweb.fr/france/fr/?page=maladies\&mal=18. Ce réseau est stable dans le temps et produit des données fiables.

- Les données du Programme de Médicalisation du Système Informatique (PMSI), qui permet une surveillance des formes disséminées de borréliose de Lyme.

L’incidence annuelle moyenne de la borréliose de Lyme estimée par le Réseau Sentinelles en France métropolitaine était de 53/100 000 habitants entre 2009 et 2017, toutes formes confondues (95\% d'EM et $5 \%$ de formes disséminées précoces ou tardives), avec un maximum à 84/100 000 en 2016. Il n'est pas possible de confirmer ou infirmer une tendance à la hausse en France. L'analyse du PMSI montre une incidence de 1,3 hospitalisations/100 000 habitants/an sur la période 2005-2017 en France métropolitaine dont la moitié pour des formes neurologiques. Ce taux fluctuait de 1,1 pour 100000 habitants/an en 2005 à 1,5 pour 100000 habitants/an en 2011 et 2017, sans tendance significative. Le taux moyen d'hospitalisation pour neuroborréliose de Lyme entre 2005 et 2017 était de 0,7/100 000 habitants/an. La majorité des cas sont diagnostiqués ou hospitalisés entre mars et novembre, avec un pic en juillet pour les formes diagnostiquées en ville et entre juillet et septembre pour les hospitalisations [15].

La borréliose de Lyme est présente sur l'ensemble du territoire métropolitain. L'Alsace, la Lorraine et le Limousin sont les régions les plus touchées, alors que le pourtour méditerranéen présente les incidences les plus basses, quelles que soient les sources de données (Figure 3). La borréliose de Lyme n'a jamais été documentée dans les DOM-TOM: les conditions climatiques sont peu propices au vecteur Ixodes. La maladie est plus fréquente chez les personnes âgées de plus de 60 ans, mais les enfants de moins de 15 ans sont plus souvent hospitalisés pour une neuroborréliose. Aucun décès n'a été rapporté lors de séjour hospitalier pour borréliose de Lyme entre 2005 et 2017 selon le PMSI. Les exceptionnels décès rapportés dans la littérature mondiale font suite à des manifestations cardiaques ou neurologiques. Une étude danoise récente a montré que la mortalité à long terme des patients atteints de neuroborréliose n'était pas différente de celle de la population générale [16]. 
Les pays voisins de la France ayant un système de surveillance similaire (sentinelle) présentent des estimations proches, avec une incidence annuelle des EM de 89/100 000 habitants pour la Belgique en 2017, 113/100 000 habitants pour la Suisse en 2014 (66/100 000 en France en 2017). En Allemagne, la maladie est à déclaration obligatoire dans 9 régions, avec une incidence moyenne de 33/100 000 habitants entre 2013 et 2017 [17], probablement sous-estimée au vu de la séroprévalence (9,4\% entre 2008 et 2011 chez des adultes en population générale) [18].

Le risque professionnel est décrit pour les travailleurs en milieu extérieur, mais la littérature est pauvre sur la quantification de la part attribuable aux expositions professionnelles. Des séroprévalences élevées ont été rapportées chez les forestiers: 14,1\% dans le nord-est de la France [19], 15,2\% en Ile de France [20], 21,6\% en Belgique, 22\% en Pologne [21, 22], et 28\% aux Pays-Bas [23]. Dans cette dernière étude, la séroprévalence était de $5 \%$ dans le groupe témoin (personnels administratifs, $P<0,01$ ). Toutefois, l'incidence des borrélioses de Lyme avec des manifestations cliniques en milieu professionnel est mal connue, probablement sous-évaluée [24]. En France, la borréliose de Lyme fait l'objet de deux tableaux de maladie professionnelle (tableau 19 du régime général et 5bis du régime agricole), définie par des manifestations cliniques, et confirmée par sérologies. En 2015, il y a eu 9 maladies professionnelles reconnues au titre du tableau 19 (leptospiroses et borréliose de Lyme) et 39 (borréliose de Lyme exclusivement).

\subsection{Autres maladies transmises par les tiques}

Les autres maladies transmises par les tiques sont beaucoup moins fréquentes: en 2003, dans une population à haut risque comme les forestiers du nord-est de la France, la séroprévalence était de 5,7\% pour Francisella tularensis, 2,3\% pour l'encéphalite à tiques, 1,7\% pour Anaplasma phagocytophilum, 0,1\% pour Babesia divergens et 2,5\% pour Babesia microti, vs 14,1\% pour Borrelia burgdorferi [19].

Le virus de l'encéphalite à tique (tick-borne encephalitis, TBE) est également transmis par Ixodes. La maladie est endémique dans plusieurs pays limitrophes de la France, dont la Suisse, certaines régions d'Allemagne et la plupart des pays d'Europe de l'Est. En France, l'incidence reste faible, avec moins d'une vingtaine de cas rapportés annuellement, essentiellement en Alsace. Une augmentation a été notée en 2016 et de nouvelles zones de circulation du virus ont été documentées, notamment dans les Alpes [25].

Les rickettsioses du groupe 'boutonneux' transmises par les tiques sont rares en France, majoritairement transmises par Rhipicephalus et Dermacentor. La plus fréquente est due à Rickettsia conorii, agent de la Fièvre Boutonneuse Méditerranéenne (FBM), transmise par la tique du chien (Rhipicephalus sanguineus), présente sur le pourtour du bassin méditerranéen entre le printemps et l'été. Une dizaine de cas sont diagnostiqués chaque année. Le Scalp Eschar associated with Neck Lymphadenopathy after Tick bite (SENLAT), également appelé Tick-Borne LymphAdenitis (TIBOLA), est 
causé principalement par Rickettsia slovaca. Les Lymphangitis-associated Rickettsia (LAR), sont dues à Rickettsia sibirica sous-espèce mongolotimonae. Ces 2 rickettsioses sont transmises par Dermacentor, présente sur l'ensemble du territoire, à l'origine de moins de 10 cas/an en France (https://www.mediterranee-infection.com/diagnostic/les-centres-nationaux-de-reference-cnr/cnrrickettsioses/rapports-dactivites/).

La tularémie est une maladie à déclaration obligatoire, principalement transmise par contact de la peau avec des animaux infectés (lièvres notamment), des végétaux, le sol ou du matériel contaminés. Chaque année, entre 50 et 100 cas de tularémie sont déclarés en France, dont 20\% après une piqûre de tique.

La babésiose est une maladie parasitaire transmise par Ixodes ricinus en Europe, fréquente chez l'animal (notamment les bovins), mais exceptionnelle chez l'Homme. En Europe, moins de 50 cas humains ont été rapportés [26]. Une quinzaine de cas liés à Babesia divergens ont été décrits en France.

L'anaplasmose granulocytaire humaine (AGH) est également transmise par Ixodes ricinus. Essentiellement diagnostiquée dans le Grand Est, elle est à l'origine d'une dizaine de cas par an [27].

Borrelia miyamotoi est présente dans les tiques Ixodes ricinus en France, mais aucun cas humain n'a été documenté, probablement du fait d'une mauvaise compétence vectorielle. De très rares cas ont été rapportés en Europe, mais de nombreux cas sont décrits en Russie, transmis par Ixodes persulcatus, plus compétent pour la transmission de cette borréliose.

Seulement 18 cas d'infections symptomatiques à Candidatus Neoehrlichia mikurensis ont été rapportés en Europe [28], dont 16 chez des immunodéprimés. Aucun cas n'a été diagnostiqué en France, mais la bactérie y a été détectée dans les tiques Ixodes.

La Fièvre Hémorragique Crimée Congo (FHCC) est transmise par la tique Hyalomma marginatum, présente sur le littoral méditerranéen. Le virus n'a jamais été mis en évidence dans les tiques en France. Cependant, des cas ont été rapportés en Grèce, en Bulgarie, en Turquie et en Espagne (3 cas en 2016 et 2018, dont un par transmission nosocomiale) [29]. La transmission par piqûre de tique de Coxiella burnetii, agent de la fièvre Q, n'a jamais été documentée. Seuls 3 cas de bartonelloses à Bartonella henselae probablement transmis par des tiques ont été décrits en France, provoquant une maladie aiguë de type SENLAT [30]. Malgré la présence possible de ces agents infectieux dans les tiques en France [31], leur compétence vectorielle pour une transmission à l'Homme n'est pas démontrée [32]. Une piqûre de tique lors d'un séjour à l'étranger peut exposer à d'autres maladies nécessitant un avis spécialisé.

\section{Dans quelles circonstances faut-il évoquer une borréliose de Lyme ou une autre maladie transmise par les tiques?}


Toutes les situations cliniques nécessitent une prise en charge globale, prenant en compte le contexte, l'environnement, les habitudes du patient et son histoire clinique. C'est dans le cadre d'une approche centrée sur le patient, après prise en compte de son point de vue, que le projet de soins pourra être élaboré et partagé [33]. L'approche holistique et centrée sur le patient n'exonère pas le médecin d'un raisonnement clinique rigoureux prenant en compte les prévalences attendues des pathologies en fonction des signes [34]. Nous proposons une approche tenant compte des symptômes évocateurs de borréliose de Lyme (Tableau 2), pour lesquels le diagnostic doit être évoqué d'emblée. D'autres symptômes, exceptionnellement décrits au cours de la borréliose de Lyme, doivent prioritairement faire évoquer d'autres diagnostics.

\subsection{Quels signes cutanés doivent faire évoquer une borréliose de Lyme?}

Ce sont les manifestations les plus fréquentes de la borréliose de Lyme, qui comporte trois types de lésions cutanées, avec des diagnostics différentiels (Tableau 2).

\subsection{1 Érythème migrant unique (phase localisée), ou multiple (phase disséminée précoce [35])}

Un EM doit être évoqué devant les arguments suivants: macule de couleur rose à rouge, ovalaire, avec éclaircissement central (inconstant), de croissance régulière (taille souvent $>5 \mathrm{~cm}$ au moment du diagnostic), d'extension centrifuge, non prurigineuse, avec trace de la piqûre centrale, inconstante (grade B). La présence de plusieurs macules érythémateuses, notamment chez un enfant, évoque un EM multiple (EMM), rare en France. L'EM et l'EMM peuvent s'accompagner d'un syndrome pseudo-grippal [36]. Aucun examen complémentaire n'est nécessaire: la sérologie est le plus souvent négative et l'histologie peu spécifique [32] (grade B).

\subsubsection{Lymphocytome borrélien [37]}

Un lymphocytome borrélien (phase disséminée précoce) doit être évoqué devant les arguments suivants: plaque ou nodule solitaire, de croissance très lente, infiltrée, de couleur variable (du rose au rouge soutenu, violine ou rouge-brun), asymptomatique (ou un peu prurigineux), de siège particulier (lobule de l'oreille chez l'enfant [38], plaque aréolaire chez l'adulte, exceptionnellement visage, tronc ou membre) (grade B). Un syndrome pseudo-grippal peut être présent. Une biopsie cutanée est utile (infiltrat lymphocytaire dense du derme) pour éliminer les diagnostics différentiels (grade $\boldsymbol{A E}$ ). La sérologie Borrelia est généralement positive.

\subsubsection{Acrodermatite chronique atrophiante (ACA) [39, 40]}

L'ACA (phase tardive disséminée) doit être évoquée chez un adulte de plus de 50 ans, devant une macule ou plaque, sur un segment de membre, de couleur variable (rouge sombre ou violacé), se renforçant en regard des surfaces osseuses, évoluant d'une phase initiale œdémateuse (empâtement) vers l'atrophie (aspect anormalement fin, plissé et brillant de la surface de la peau), grade $\boldsymbol{A E}$. Des zones plus infiltrées (nodules fibreux ou bandelettes fibreuses périarticulaires) et une douleur déclenchée par l'effleurement 
(allodynie) sont évocatrices. Une zone de sclérose (induration) est possible [41]. La sérologie Borrelia est toujours positive, avec des titres d'IgG élevés. La biopsie cutanée peut contribuer au diagnostic (anomalies du collagène, télangiectasies, infiltrat interstitiel avec plasmocytes) [42].

\subsection{Quelles manifestations neurologiques doivent faire évoquer une neuroborréliose?}

Les atteintes neurologiques sont les plus fréquentes en France (6,5-15\% des borrélioses de Lyme) après les manifestations cutanées. Elles surviennent durant la phase disséminée précoce ( $<6$ mois $)$ dans $>90 \%$ des cas [43] (grade B). En Europe, les neuroborrélioses sont dues à Borrelia garinii dans 2/3 des cas et Borrelia afzelii dans un 1/4 des cas.

\subsubsection{Quand évoquer et comment confirmer une neuroborréliose?}

Toute manifestation neurologique dans les suites d'un EM non traité ou d'une piqûre de tique doit faire évoquer une neuroborréliose (grade $\boldsymbol{A E}$ ). Le diagnostic repose sur la sérologie en deux temps et sur l'index anticorps du liquide cérébrospinal (LCS) [44] (Tableau 3) (grade B). La ponction lombaire objective une méningite lymphocytaire. L'index de synthèse intrathécale est un rapport qui prend en compte les taux d'Ac spécifiques LCS/sérum et d'IgG totales LCS/sérum. Dans les neuroborrélioses tardives, la sérologie et l'index anticorps sont toujours positifs et indispensables au diagnostic [45] (grade B). La PCR Borrelia dans le LCS présente une sensibilité trop faible (10-30\%) pour être recommandée au-delà de 6 semaines d'évolution des symptômes [46] (grade B).

\subsubsection{Formes cliniques évocatrices de neuroborréliose}

Les principales neuroborrélioses de Lyme sont les méningoradiculites et les atteintes de nerfs crâniens, principalement du nerf facial [43, 47, 48]. Ces manifestations doivent faire envisager une neuroborréliose quel que soit le contexte (grade A):

- Les méningoradiculites (syndrome de Garin-Bujadoux ou de Bannwarth) représentent 67 à $85 \%$ des neuroborrélioses en Europe. Elles sont responsables de douleurs radiculaires atypiques, rebelles, insomniantes, qui peuvent dépasser le territoire radiculaire. Elles touchent souvent le tronc. Leur localisation dans la région d'une piqûre de tique ou d'un EM est évocatrice. Un déficit sensitif et un déficit moteur éventuellement retardé sont possibles. Une paralysie faciale est fréquemment associée, ainsi que des céphalées [43, 45]. La présence d'une méningite lymphocytaire avec index anticorps positif est un élément déterminant du diagnostic [43]. Les douleurs peuvent durer des mois en l'absence de traitement. L'antibiothérapie est typiquement très efficace en quelques jours sur la symptomatologie douloureuse.

- La paralysie faciale périphérique représente plus de 36\% des neuroborrélioses en Europe. L'atteinte isolée d'un autre nerf crânien (oculomoteur, optique) est beaucoup plus rare. La paralysie faciale est bilatérale dans 1/3 des cas, asynchrone. Elle touche surtout l'enfant chez lequel la borréliose de Lyme représente 30\% des causes de paralysies faciales en zone d'endémie. Une sérologie Borrelia doit être systématique. Une 
ponction lombaire doit être discutée devant toute paralysie faciale périphérique chez l'enfant en zone d'endémie surtout en cas d'exposition aux piqûres de tiques dans les semaines précédentes (grade AE). Chez l'adulte, devant une paralysie faciale isolée (sans céphalée ni autre signe d'accompagnement), la sérologie Borrelia doit également être systématique, mais ne doit pas retarder l'instauration de la corticothérapie, dont l'efficacité dans la paralysie faciale a frigore n'a été montrée que si elle est précoce (grade $\boldsymbol{A E}$ ). En cas de sérologie positive en ELISA, une ponction lombaire sera réalisée (grade AE).

\subsubsection{Formes cliniques compatibles avec une neuroborréliose, mais beaucoup plus rares}

Les méningites cliniques, les myélites aiguës et les encéphalites, beaucoup plus rares [48], doivent faire évoquer une neuroborréliose en cas de facteur de risque d'exposition (grade B). Les formes tardives diagnostiquées après plus de 6 mois d'évolution concernent 1 à $9 \%$ des cas.

- L'atteinte méningée isolée (5\% des neuroborrélioses) se traduit par des céphalées et des nausées avec plus rarement des signes méningés. L'étude du LCS montre une méningite lymphocytaire, une hyperprotéinorachie, une normoglycorachie, et inconstamment une distribution oligoclonale des Ig.

- Les myélites transverses aiguës ( $<5 \%$ des neuroborrélioses), étendues sur plusieurs segments, prédominent en région cervicale.

- Les encéphalites aiguës ou subaiguës représentent $6 \%$ des neuroborrélioses ayant donné lieu à une hospitalisation [49]

- Les atteintes cérébrovasculaires ( $<1 \%$ des neuroborrélioses) peuvent survenir à la phase disséminée précoce ou tardive.

- Les polyneuropathies axonales sensitives asymétriques (phase disséminée tardive) sont associées à une ACA. Une polyneuropathie symétrique distale longueur-dépendante ne rentre pas dans le cadre d'une neuroborréliose [43].

- Des encéphalomyélites chroniques (durée >6 mois) en rapport avec une atteinte méningovasculaire ont été rarement rapportées. Le tableau est celui d'une méningite chronique avec céphalées, amaigrissement, troubles neurosensoriels, et marche ataxo-spasmodique [50].

- La neuroborréliose est une cause très rare de troubles cognitifs et de démences, même en région de prévalence élevée de la maladie de Lyme [51]. Sa curabilité justifie néanmoins qu'elle soit recherchée en l'absence d'autre étiologie (grade $\boldsymbol{A E}$ ).

\subsection{Quelles manifestations rhumatologiques doivent faire évoquer une borréliose?}

\subsubsection{Symptômes articulaires}

Des arthralgies surviennent fréquemment (50-70\%) durant les phases précoces. Lors de la phase disséminée, la manifestation articulaire caractéristique de la borréliose de Lyme est une monoarthrite, touchant dans $85 \%$ des cas le genou, plus rarement une oligoarthrite. C'est une arthrite subaiguë avec mise en charge possible, voire compatible avec la marche (Figure 5). Elle survient quelques semaines à deux ans après la piqûre. En l'absence d'antibiothérapie adaptée, l'atteinte articulaire évolue par poussées successives 
entrecoupées de périodes de rémission [52-54], et $10 \%$ évoluent vers une forme chronique. Les poussées d'arthrites persistent quelques semaines ou mois, avec une fréquence diminuant au cours du temps. La guérison survient dans les 5 ans, même en l'absence d'antibiothérapie. En Amérique du Nord, l'arthrite est précédée dans $50 \%$ des cas d'un EM, alors que cet antécédent n'est présent que chez $20 \%$ des patients en Europe. La notion de piqûre de tique est inconstante ( $<25 \%$ des cas).

\subsubsection{Symptômes musculaires}

Ils sont remarquables par leur polymorphisme clinique, une atteinte localisée, et l'association à d'autres manifestations de la maladie (neurologiques, articulaires, ACA). Des myalgies chroniques ont été décrites, associées à la présence d'ADN (PCR) dans le muscle, sans que leur mécanisme ait été précisé (5). Une myosite vraie semble très rare.

\subsubsection{Manifestations atypiques}

De nombreuses manifestations articulaires atypiques ont été rapportées (polyarthrites, enthésopathies axiales et/ou périphériques), avec de faibles niveaux de preuve, notamment un diagnostic basé uniquement sur la sérologie, très rarement documenté par la présence de Borrelia burgdorferi dans les articulations ou tendons.

\subsection{Quelles manifestations cardiologiques doivent faire évoquer une borréliose de Lyme (Tableau 4)?}

Une atteinte cardiaque complique la borréliose de Lyme dans 0,3-4\% des cas, mais cette prévalence pourrait atteindre $10 \%$ aux États-Unis [55, 56]. La prévalence documentée par l'histopathologie dans les modèles animaux est supérieure à celle retrouvée chez l'homme par la clinique [56, 57]. Ces manifestations cardiaques surviennent avec un délai variable au décours de l'EM (médiane, 21 jours ; extrêmes, 7 jours-7 mois) [56]. L'atteinte cardiaque peut être asymptomatique ou au premier plan, inaugurale [58]. L'évolution est favorable dans $90 \%$ des cas, mais les troubles de la conduction peuvent nécessiter une stimulation cardiaque temporaire dans $30 \%$ des cas, plus rarement définitive, en particulier chez des patients âgés.

\subsubsection{Troubles de la conduction}

Les manifestations cardiaques les plus fréquentes sont les blocs auriculo-ventriculaires (BAV) de siège nodal (44\% des cas), à type de BAV-3 (49\%), de BAV-2 (16\%) et de BAV-1 (12\%) [55] (grade B). Le siège infranodal et les atteintes fasciculaires, blocs de branche droit ou gauche, sont plus rares. Des blocs sinoauriculaires et des troubles rythmiques, fibrillation atriale, tachycardie supraventriculaire ou ventriculaire, ont été rapportés [55, 59, 60].

\subsubsection{Atteinte myocardique}


Une myocardite, une dysfonction ventriculaire gauche ou une insuffisance cardiaque sont très rarement rattachées à une borréliose de Lyme (grade B). Celle-ci peut être évoquée en l'absence d'autre cause. La prévalence des myocardites est estimée à 0,4-4\% des borrélioses de Lyme en Europe [59]. La dysfonction ventriculaire gauche est modérée ou discrète en échocardiographie. Elle peut s'accompagner de modifications de la repolarisation à l'ECG et d'élévation des biomarqueurs (troponine, BNP, NT-proBNP) [59].

\subsubsection{Péricardites}

Une péricardite serait observée dans $23 \%$ des atteintes cardiaques de la borréliose de Lyme [61], et doit être recherchée en cas de péricardite d'étiologie indéterminée (grade $\boldsymbol{A E}$ ).

\subsection{Quelles manifestations ophtalmologiques doivent faire évoquer une borréliose?}

Les manifestations ophtalmologiques de la borréliose de Lyme sont mal connues. La plupart des observations reposent sur des arguments sérologiques, ce qui rend incertaine l'imputabilité des manifestations ophtalmologiques à une borréliose. De rares observations confirment le tropisme de Borrelia burgdorgeri pour l'œil avec PCR positive dans un tissu oculaire, ou manifestations ophtalmologiques (uvéites) concomitantes d'une neuroborréliose confirmée par l'analyse du LCS [62-64].

3.6 Devant une autre manifestation non typiquement évocatrice de borréliose de Lyme: quelle est la conduite à tenir?

Il n'est pas licite d'envisager systématiquement une borréliose de Lyme devant des manifestations aussi courantes que la fatigue, des céphalées ou des crampes. Un patient consultant pour ces motifs, y compris dans une région à forte prévalence, a nettement plus de probabilité de souffrir d'une autre maladie. La borréliose de Lyme est souvent envisagée par excès, en particulier si l'approche est centrée exclusivement sur les maladies transmises par les tiques, ce qui peut altérer le raisonnement. De cette altération découle le concept d'heuristique d'ancrage: «processus cognitif où un individu se fie trop fortement à un élément d'information initial (le point d'ancrage), sans ajustement devant des informations nouvelles ». Ce biais cognitif peut aboutir à retenir l'hypothèse d'une borréliose de Lyme, sans réévaluation de la probabilité de celle-ci même lorsque les tests diagnostiques et la réponse au traitement devraient la faire reconsidérer. Le biais de clôture prématurée, consistant à ne pas explorer l'ensemble des hypothèses, s'en rapproche $[34,65]$. Ces biais de raisonnement peuvent conduire à des examens et traitements inutiles.

Lorsqu'une hypothèse diagnostique ne peut être confirmée, il n'est pas raisonnable d'envisager une hypothèse alternative beaucoup moins plausible comme la borréliose de Lyme, sauf si l'évolution des symptômes ou le résultat d'examens complémentaires remet en cause l'hypothèse initiale. Toutefois, 
l'association de plusieurs conditions morbides peut parfois expliquer le tableau clinique. Dans une récente cohorte en France, 10\% des patients consultant pour suspicion de borréliose Lyme avaient des douleurs ostéo-articulaires liées à de l'arthrose ou une scoliose [66].

\subsection{Dans quelles circonstances faut-il évoquer une autre maladie vectorielle à tiques?}

Les autres maladies vectorielles à tiques provoquent des tableaux cliniques aigus (Tableau 5). Ces infections étant rares en France, il est conseillé de prendre l'avis d'un infectiologue.

\subsubsection{Encéphalite à tique}

L'infection par le virus TBE est le plus souvent asymptomatique. Lorsqu'ils sont présents, les signes cliniques évoluent classiquement en 2 phases, après une incubation de 7-14 jours (maximum, 4 semaines). La première phase associe fièvre, myalgies et céphalées. Après une amélioration spontanée avec un intervalle libre d'environ une semaine, $1 / 3$ des patients développent une deuxième phase fébrile avec signes méningés et encéphalitiques (confusion, somnolence, troubles de l'équilibre, tremblements des extrémités, troubles de l'élocution ou syndrome cérébelleux) (grade B). Des myélites ou méningoradiculites sont rapportées.

Le diagnostic repose sur la ponction lombaire, qui objective une méningite lymphocytaire. La détection d'IgM spécifiques dans le sérum, voire le LCS, confirme le diagnostic (grade B). Les IgM apparaissent lors des 6 premiers jours des symptômes neurologiques et peuvent persister 10 mois. Les IgG peuvent être détectés à vie dans le sérum. La maladie est immunisante à long terme.

Il n'existe pas de traitement curatif: la prise en charge repose sur le traitement symptomatique. L'évolution est favorable dans la majorité des cas, mais $10 \%$ des patients présentent des séquelles neurologiques. La mortalité est de 0,5 à $2 \%$. Un vaccin efficace est disponible, mais il n'est recommandé en France que pour les séjours avec exposition en zone d'endémie.

\subsubsection{Rickettsioses transmises par les tiques}

Le signe commun à toutes les rickettsioses du groupe boutonneux est la présence d'une escarre d'inoculation au site de la piqûre de tique avec des signes cliniques apparaissant moins d'une semaine après la piqûre (grade B). Dans la FBM (Rickettsia conorii), cette escarre s'accompagne d'une fièvre, de céphalées, de myalgies et d'une éruption maculo-papuleuse diffuse n'épargnant pas les paumes et les plantes. Des formes graves sont décrites dans 5\% des cas avec défaillance(s) d'organe(s) et coagulation intravasculaire disséminée (CIVD), chez des patients âgés et/ou avec comorbidités: diabète, éthylisme, déficit en G6PD.

Rickettsia sibirica mongolotimonae provoque un tableau similaire associant fièvre, céphalées, myalgies, escarre d'inoculation et éruption maculo-papuleuse. Une traînée de lymphangite allant de 
l'escarre à l'adénopathie satellite, douloureuse, réalise le tableau de LAR. Dans le SENLAT ou TIBOLA (Rickettsia slovaca et Rickettsia raoulti principalement), l'escarre d'inoculation est présente au niveau du cuir chevelu, associée à des céphalées, une fébricule et des adénopathies cervicales douloureuses.

Le diagnostic des rickettsioses repose sur la sérologie qui doit être répétée 3 semaines plus tard (grade B). Une PCR Rickettsia peut être effectuée sur biopsie cutanée ou écouvillon de l'escarre d'inoculation (grade B), CNR des Rickettsies: https://www.mediterranee-infection.com/conduite-a-tenirlors-dune-piqûre-de-tique/).

Le traitement de première intention des rickettsioses transmises par les tiques est la doxycycline, 200 $\mathrm{mg} / \mathrm{j}$ chez l'adulte ou $4 \mathrm{mg} / \mathrm{kg} / \mathrm{j}$ chez l'enfant, à poursuivre $48 \mathrm{~h}$ après l'obtention de l'apyrexie. Chez l'enfant de moins de 8 ans et la femme enceinte, l'azithromycine, $10 \mathrm{mg} / \mathrm{kg} / \mathrm{j}$ pendant 3 jours, est privilégiée. Il est recommandé de proposer un traitement empirique devant un tableau d'escarre avec fièvre et éruption cutanée du fait de la sévérité possible de la FBM (grade B). Le pronostic des rickettsioses transmises par les tiques est favorable à l'exception des formes graves de FBM. Dans le cas du SENLAT, les adénopathies cervicales et l'asthénie peuvent persister plusieurs semaines.

\subsubsection{Tularémie}

Les symptômes débutent entre 1 et 14 jours après l'inoculation. La forme la plus fréquente est ulcéro-ganglionnaire avec initialement un tableau de fièvre et myalgies diffuses, suivi d'une ulcération au site d'inoculation avec adénopathie(s) satellite(s). Les autres formes - oculo-ganglionnaire, oropharyngée, ou pulmonaire - sont liées à d'autres modes de transmission. Le diagnostic repose sur la sérologie par immunofluorescence indirecte ou microagglutination, les anticorps apparaissant en 2-3 semaines. La détection de Francisella tularensis par culture ou PCR est possible (hémocultures, ponction ganglionnaire). Les prélèvements doivent être adressés au CNR des Francisella pour confirmation. Classé comme microorganisme hautement pathogène, sa manipulation nécessite un laboratoire de sécurité biologique. Le traitement repose sur la doxycycline, $200 \mathrm{mg} / \mathrm{j}$ ou la ciprofloxacine, $500 \mathrm{mg}$ x 2/j, pendant 14 jours. Une association avec un aminoside se discute en cas de forme grave ou d'évolution défavorable.

\subsubsection{Babésiose}

Chez l'immunocompétent, la babésiose est le plus souvent asymptomatique. Les formes symptomatiques se présentent 1 à 4 semaines après la piqûre de tique par un tableau associant une fièvre élevée, des céphalées et des myalgies (grade $\boldsymbol{A} \boldsymbol{E}$ ). Des tableaux plus sévères sont décrits (hémolyse, insuffisance médullaire, hépatopathie, ictère, hémoglobinurie, CIVD), notamment chez les patients aspléniques. Le diagnostic peut être fait sur l'examen du frottis sanguin par un biologiste expérimenté, mais 
la PCR est plus sensible en cas de faible parasitémie (grade AE). La sérologie restant positive des années, elle n'a pas d'intérêt en l'absence de symptômes évocateurs: une sérologie positive est alors le témoin d'une infection ancienne et guérie. Le traitement dépend de l'espèce et nécessite un avis spécialisé. Il repose sur l'association clindamycine et quinine, ou azithromycine et atovaquone. L'artémisinine n'a pas été étudiée pour les babésioses et n'est pas recommandée.

\subsubsection{L'Anaplasmose granulocytaire humaine}

Le tableau associe fièvre, arthromyalgies, céphalées, frissons, thrombocytopénie, leucopénie et cytolyse hépatique dans les 2 semaines qui suivent une piqûre de tique (grade $\boldsymbol{B}$ ). Si la pathologie est généralement spontanément résolutive dans les 30 jours, des formes sévères ont été décrites aux États-Unis avec défaillance multi-viscérale chez des patients atteints de néoplasie. Le diagnostic repose sur une PCR spécifique dans le sang, prélevé à la phase fébrile, envoyé au CNR des Borrelia: http://www.chrustrasbourg.fr/Les-centres-de-reference/Borrelia ou CNR des Rickettsia: https://www.mediterraneeinfection.com/conduite-a-tenir-lors-dune-piqûre-de-tique). La sérologie par immunofluorescence indirecte permet le diagnostic en cas de séroconversion (multiplication par 4 du taux d'anticorps) ou de taux >1/256, à distance de la fièvre. Il faut répéter la sérologie 3 semaines après le début des symptômes. Le traitement repose sur la doxycycline, $200 \mathrm{mg} / \mathrm{j}$ chez l'adulte ou $4 \mathrm{mg} / \mathrm{kg} / \mathrm{j}$ chez l'enfant de plus de 8 ans, pendant 7 jours (alternative, rifampicine, $300 \mathrm{mg}$ x 2/j). Il n’y a pas d'échec de traitement documenté.

\subsubsection{Autres maladies transmises par les tiques avec risque d'émergence en France}

La FHCC est une fièvre hémorragique virale dont le tableau débute 3-7 jours après la piqûre par une fièvre avec myalgies, hyperhémie de la face et du cou, conjonctivite et signes digestifs. Cette phase d'environ 3 jours peut être suivie d'une phase hémorragique durant 2-3 jours, de sévérité variable, avec thrombopénie, leucopénie, et cytolyse hépatique. Une transmission interhumaine est possible, y compris au personnel soignant, si les mesures de précautions d'hygiène et d'isolement ne sont pas appliquées.

La fièvre récurrente à Borrelia myiamotoi débute environ 2 semaines après une piqûre de tique Ixodes et associe fièvre, asthénie, céphalées et myalgies. Des récurrences fébriles peuvent survenir avec des intervalles de 9 jours en moyenne (grade B). Les complications neurologiques, oculaires, hématologiques, sont exceptionnelles et concernent des patients fortement immunodéprimés (3 cas rapportés en Europe). L'infection peut causer des complications pendant la grossesse. Le traitement de choix est la doxycycline.

Des cas d'infection symptomatique à Candidatus Neoerhlichia mikurensis ont été rapportés chez des immunodéprimés (patients d'hématologie ou de rhumatologie sous immunosuppresseurs). Elle provoque une fièvre avec myalgies et arthralgies (grade B). Le diagnostic se fait par PCR dans le sang (CNR des 
Borrelia ou des Rickettsia), la bactérie étant incultivable. Il n'existe pas de sérologie à l'heure actuelle. Les cas rapportés ont été traités par doxycycline avec une disparition des symptômes après 5 jours de traitement en moyenne [28]. 


\section{Conflits d'intérêt:}

C. Lemogne a participé à un conseil scientifique pour Lundbeck, a bénéficié de financements de Lundbeck et Otsuka Pharmaceutical pour des congrès ou des activités de recherche, et d'une rémunération personnelle de Daiichi-Sankyo, Janssen-Cilag, Lundbeck et Servier pour une intervention ou un travail ciblé. V. Hentgen a participé à des conseils scientifiques pour Novartis pharma, SOBI et ABBVE, a bénéficié de financements de Novartis pharma pour des congrès ou des activités de recherche, et d'une rémunération personnelle de Novartis pharma pour une intervention. A. Saunier a bénéficié de financements de Novartis, Gilead, ViiV Healthcare, Genzyme, LFB Médicaments, pour des congrès ou des activités de recherche, et d'une rémunération personnelle de Novartis et Ceformed pour des interventions. K. Bouiller a bénéficié d'une rémunération personnelle de Ceformed pour des formations. P. Cathebras a bénéficié de financements de Sanofi-Genzyme, GSK, Novartis et LFB pour des congrès, et d'une rémunération personnelle de MSD, ADEPUL, et MG-Form pour des interventions. C. Eldin a bénéficié de financements de Sanofi-Genzyme, GSK, Novartis et LFB pour des congrès, et d'une rémunération personnelle de MSD, ADEPUL, et MGForm pour des interventions. B. Jaulhac est intervenu comme expert ponctuel pour l'ANSM, la HAS, l'ECDC. Il a participé au développement d'un brevet de vaccin contre la maladie de Lyme canine $\left(\mathrm{N}^{\circ}\right.$ 1551182). B. Fantin a participé à un conseil scientifique pour Novartis, et bénéficié de financements recherche/congrès de Eumedica. B. Bodaghi a participé à un conseil scientifique pour AbbVie, Allergan, et a bénéficié de financements de Santen, AbbVie, Allergan, Bayer, et Thea, pour des congrès ou des activités de recherche. J.-P. Gangneux a participé à un conseil scientifique pour Pfizer, MSD, et a bénéficié de financements de Pfizer, MSD, pour des congrès ou des activités de recherche. H. Partouche a bénéficié de financements de Pfizer, pour un congrès et un projet de recherche. F. Sellal a bénéficié de financements de Biogen-Idec, Roche, TEVA, Sanofi, Elivie, pour des congrès ou des activités de recherche, et d'une rémunération personnelle de Novartis-Pharma, Sanofi, Lundbeck, Eisai, et TEVA. C. Chirouze a bénéficié de financements de Astellas, Gilead, ViiV Helathcare, MSD et Janssen pour des congrès ou des activités de recherche, et d'une rémunération personnelle de BMS pour une intervention. A. Raffetin a bénéficié de financements de MSD et Elivie pour des congrès ou des activités de recherche. C. Rabaud a participé à des conseils scientifiques pour MSD, GSK, Pfizer, AstraZeneca, Janssen, Astellas, Gilead, et Viiv Healthcare, et bénéficié de financements de Mylan, Astellas, Janssen, MSD, et Gilead, pour des congrès ou des activités de recherche. F. Roblot a participé à des conseils scientifiques pour Janssen, bénéficié de financements de Astellas, Eumedica, Novartis, Pfizer, Sanofi et MSD, pour des congrès ou des activités de recherche, et d'une rémunération de GSK, MSD et Astellas pour des interventions ponctuelles. P. Tattevin a participé à des conseils scientifiques pour Gilead, Astellas, Coreviome, MSD, Mylan, et Pfizer, bénéficié de financements de Astellas, Biomérieux, Gilead, Pfizer, et MSD, pour des congrès ou des activités de recherche, et d'une rémunération de Mylan, MSD, Pfizer, Biomérieux, Gilead, et Astellas pour des interventions ponctuelles. 


\section{Références}

1. Hilger C, Bessot JC, Hutt N, Grigioni F, De Blay F, Pauli G, et al. IgE-mediated anaphylaxis caused by bites of the pigeon tick Argas reflexus: cloning and expression of the major allergen Arg r 1. J Allergy Clin Immunol 2005,115:617-622.

2. Boulanger N, Boyer P, Talagrand-Reboul E, Hansmann Y. Ticks and tick-borne diseases. Med Mal Infect 2019.

3. Jones EH, Hinckley AF, Hook SA, Meek JI, Backenson B, Kugeler KJ, et al. Pet ownership increases human risk of encountering ticks. Zoonoses Public Health 2018,65:74-79.

4. Parola P, Socolovschi C, Jeanjean L, Bitam I, Fournier PE, Sotto A, et al. Warmer weather linked to tick attack and emergence of severe rickettsioses. PLoS Negl Trop Dis 2008,2:e338.

5. Eisen L, Dolan MC. Evidence for Personal Protective Measures to Reduce Human Contact With Blacklegged Ticks and for Environmentally Based Control Methods to Suppress Host-Seeking Blacklegged Ticks and Reduce Infection with Lyme Disease Spirochetes in Tick Vectors and Rodent Reservoirs. J Med Entomol 2016.

6. Pages F, Dautel H, Duvallet G, Kahl O, de Gentile L, Boulanger N. Tick repellents for human use: prevention of tick bites and tick-borne diseases. Vector Borne Zoonotic Dis 2014,14:85-93.

7. Montemarano AD, Gupta RK, Burge JR, Klein K. Insect repellents and the efficacy of sunscreens. Lancet 1997,349:1670-1671.

8. van der Rhee HJ, Farquhar JA, Vermeulen NP. Efficacy and transdermal absorption of permethrin in scabies patients. Acta Derm Venereol 1989,69:170-173.

9. Due C, Fox W, Medlock JM, Pietzsch M, Logan JG. Tick bite prevention and tick removal. Bmj 2013,347:f7123.

10. Boulanger N, Lipsker D. [Protection against tick bites]. Parasit Vectors 2015,142:245-251.

11. Schwameis M, Kundig T, Huber G, von Bidder L, Meinel L, Weisser R, et al. Topical azithromycin for the prevention of Lyme borreliosis: a randomised, placebo-controlled, phase 3 efficacy trial. Lancet Infect Dis 2017,17:322-329.

12. Stanek G, Wormser GP, Gray J, Strle F. Lyme borreliosis. Lancet 2012,379:461-473.

13. Kilpatrick AM, Randolph SE. Drivers, dynamics, and control of emerging vector-borne zoonotic diseases. Lancet 2012,380:1946-1955.

14. Kilpatrick HJ, LaBonte AM, Stafford KC. The relationship between deer density, tick abundance, and human cases of Lyme disease in a residential community. J Med Entomol 2014,51:777-784.

15. Vandenesch A, Turbelin C, Couturier E, Arena C, Jaulhac B, Ferquel E, et al. Incidence and hospitalisation rates of Lyme borreliosis, France, 2004 to 2012. Euro Surveill 2014,19.

16. Obel N, Dessau RB, Krogfelt KA, Bodilsen J, Andersen NS, Moller JK, et al. Long term survival, health, social functioning, and education in patients with European Lyme neuroborreliosis: nationwide population based cohort study. Bmj 2018,361:k1998.

17. Enkelmann J, Bohmer M, Fingerle V, Siffczyk C, Werber D, Littmann M, et al. Incidence of notified Lyme borreliosis in Germany, 2013-2017. Sci Rep 2018,8:14976.

18. Wilking $\mathrm{H}$, Fingerle V, Klier $\mathrm{C}$, Thamm M, Stark K. Antibodies against Borrelia burgdorferi sensu lato among Adults, Germany, 2008-2011. Emerg Infect Dis 2015,21:107-110.

19. Rigaud E, Jaulhac B, Garcia-Bonnet N, Hunfeld KP, Femenia F, Huet D, et al. Seroprevalence of seven pathogens transmitted by the Ixodes ricinus tick in forestry workers in France. Clin Microbiol Infect 2016,22:735.e731-739.

20. Zhioua E, Rodhain F, Binet P, Perez-Eid C. Prevalence of antibodies to Borrelia burgdorferi in forestry workers of Ile de France, France. Eur J Epidemiol 1997,13:959-962.

21. De Keukeleire M, Robert A, Luyasu V, Kabamba B, Vanwambeke SO. Seroprevalence of Borrelia burgdorferi in Belgian forestry workers and associated risk factors. Parasit Vectors 2018,11:277.

22. Kiewra D, Szymanowski M, Zalewska G, Dobracka B, Dobracki W, Klakocar J, et al. Seroprevalence of Borrelia burgdorferi in forest workers from inspectorates with different forest types in Lower Silesia, SW Poland: preliminary study. Int J Environ Health Res 2018,28:502-510.

23. Kuiper H, van Dam AP, Moll van Charante AW, Nauta NP, Dankert J. One year follow-up study to assess the prevalence and incidence of Lyme borreliosis among Dutch forestry workers. Eur J Clin Microbiol Infect Dis 1993,12:413-418.

24. Piacentino JD, Schwartz BS. Occupational risk of Lyme disease: an epidemiological review. Occup Environ Med 2002,59:75-84.

25. Velay A, Solis M, Kack-Kack W, Gantner P, Maquart M, Martinot M, et al. A new hot spot for tick-borne encephalitis (TBE): A marked increase of TBE cases in France in 2016. Ticks Tick Borne Dis 2018,9:120-125.

26. Gorenflot A, Moubri K, Precigout E, Carcy B, Schetters TP. Human babesiosis. Ann Trop Med Parasitol 1998,92:489-501. 
27. Edouard S, Koebel C, Goehringer F, Socolovschi C, Jaulhac B, Raoult D, et al. Emergence of human granulocytic anaplasmosis in France. Ticks Tick Borne Dis 2012,3:403-405.

28. Portillo A, Santibanez P, Palomar AM, Santibanez S, Oteo JA. 'Candidatus Neoehrlichia mikurensis' in Europe. New Microbes New Infect 2018,22:30-36.

29. Negredo A, de la Calle-Prieto F, Palencia-Herrejon E, Mora-Rillo M, Astray-Mochales J, Sanchez-Seco MP, et al. Autochthonous Crimean-Congo Hemorrhagic Fever in Spain. N Engl J Med 2017,377:154-161.

30. Angelakis E, Pulcini C, Waton J, Imbert P, Socolovschi C, Edouard S, et al. Scalp eschar and neck lymphadenopathy caused by Bartonella henselae after Tick Bite. Clin Infect Dis 2010,50:549-551.

31. Vayssier-Taussat M, Kazimirova M, Hubalek Z, Hornok S, Farkas R, Cosson JF, et al. Emerging horizons for tick-borne pathogens: from the 'one pathogen-one disease' vision to the pathobiome paradigm. Future Microbiol 2015,10:2033-2043.

32. Eldin C, Raffetin A, Bouiller K, Hansmann Y, Roblot F, Raoult D, et al. Review of European and American guidelines for the diagnosis of Lyme borreliosis. Med Mal Infect 2019,49:121-132.

33. Charles C, Gafni A, Whelan T. Shared decision-making in the medical encounter: what does it mean? (or it takes at least two to tango). Soc Sci Med 1997,44:681-692.

34. Nendaz M, Charlin B, Leblanc V, Bordage G. Le raisonnement clinique: données issues de la recherche et implications pour l'enseignement. Pédagogie Médicale 2005,6(4):35-54.

35. Stupica D, Maraspin V, Bogovic P, Ogrinc K, Blagus R, Cerar T, et al. Comparison of Clinical Course and Treatment Outcome for Patients With Early Disseminated or Early Localized Lyme Borreliosis. JAMA Dermatol 2018,154:1050-1056.

36. Strle F, Lusa L, Ruzic-Sabljic E, Maraspin V, Lotric Furlan S, Cimperman J, et al. Clinical characteristics associated with Borrelia burgdorferi sensu lato skin culture results in patients with erythema migrans. PLoS One 2013,8:e82132.

37. Maraspin V, Nahtigal Klevisar M, Ruzic-Sabljic E, Lusa L, Strle F. Borrelial Lymphocytoma in Adult Patients. Clin Infect Dis 2016,63:914-921.

38. Arnez M, Ruzic-Sabljic E. Borrelial Lymphocytoma in Children. Pediatr Infect Dis J 2015,34:1319-1322.

39. Brehmer-Andersson E, Hovmark A, Asbrink E. Acrodermatitis chronica atrophicans: histopathologic findings and clinical correlations in 111 cases. Acta Derm Venereol 1998,78:207-213.

40. Lenormand C, Jaulhac B, Debarbieux S, Dupin N, Granel-Brocard F, Adamski H, et al. Expanding the clinicopathological spectrum of late cutaneous Lyme borreliosis (acrodermatitis chronica atrophicans [ACA]): A prospective study of 20 culture- and/or polymerase chain reaction (PCR)-documented cases. J Am Acad Dermatol 2016,74:685-692.

41. Zollinger T, Mertz KD, Schmid M, Schmitt A, Pfaltz M, Kempf W. Borrelia in granuloma annulare, morphea and lichen sclerosus: a PCR-based study and review of the literature. J Cutan Pathol 2010,37:571-577.

42. Moreno C, Kutzner H, Palmedo G, Goerttler E, Carrasco L, Requena L. Interstitial granulomatous dermatitis with histiocytic pseudorosettes: a new histopathologic pattern in cutaneous borreliosis. Detection of Borrelia burgdorferi DNA sequences by a highly sensitive PCR-ELISA. J Am Acad Dermatol 2003,48:376-384.

43. Oschmann P, Dorndorf W, Hornig C, Schafer C, Wellensiek HJ, Pflughaupt KW. Stages and syndromes of neuroborreliosis. J Neurol 1998,245:262-272.

44. Mygland A, Ljostad U, Fingerle V, Rupprecht T, Schmutzhard E, Steiner I. EFNS guidelines on the diagnosis and management of European Lyme neuroborreliosis. Eur J Neurol 2010,17:8-16, e11-14.

45. Ogrinc K, Lusa L, Lotric-Furlan S, Bogovic P, Stupica D, Cerar T, et al. Course and Outcome of Early European Lyme Neuroborreliosis (Bannwarth Syndrome): Clinical and Laboratory Findings. Clin Infect Dis 2016,63:346353.

46. Cerar T, Ogrinc K, Cimperman J, Lotric-Furlan S, Strle F, Ruzic-Sabljic E. Validation of cultivation and PCR methods for diagnosis of Lyme neuroborreliosis. J Clin Microbiol 2008,46:3375-3379.

47. Ackermann R, Horstrup P, Schmidt R. Tick-borne meningopolyneuritis (Garin-Bujadoux, Bannwarth). Yale J Biol Med 1984,57:485-490.

48. Hansen K, Lebech AM. The clinical and epidemiological profile of Lyme neuroborreliosis in Denmark 19851990. A prospective study of 187 patients with Borrelia burgdorferi specific intrathecal antibody production. Brain 1992,115 ( Pt 2):399-423.

49. Schwenkenbecher P, Pul R, Wurster U, Conzen J, Pars K, Hartmann H, et al. Common and uncommon neurological manifestations of neuroborreliosis leading to hospitalization. BMC Infect Dis 2017,17:90.

50. Hansen K, Crone C, Kristoferitsch W. Lyme neuroborreliosis. Handb Clin Neurol 2013,115:559-575.

51. Blanc F. [Neurologic and psychiatric manifestations of Lyme disease]. Med Mal Infect 2007,37:435-445.

52. Grillon A, Scherlinger M, Boyer PH, De Martino S, Perdriger A, Blasquez A, et al. Characteristics and clinical outcomes after treatment of a national cohort of PCR-positive Lyme arthritis. Semin Arthritis Rheum 2018. 
53. Lipsker D, Hansmann Y, Limbach F, Clerc C, Tranchant C, Grunenberger F, et al. Disease expression of Lyme borreliosis in northeastern France. Eur J Clin Microbiol Infect Dis 2001,20:225-230.

54. Steere AC, Schoen RT, Taylor E. The clinical evolution of Lyme arthritis. Ann Intern Med 1987,107:725-731.

55. Steere AC. Lyme disease. N Engl J Med 2001,345:115-125.

56. Cadavid D, Bai Y, Hodzic E, Narayan K, Barthold SW, Pachner AR. Cardiac involvement in non-human primates infected with the Lyme disease spirochete Borrelia burgdorferi. Lab Invest 2004,84:1439-1450.

57. Rostoff P, Gajos G, Konduracka E, Gackowski A, Nessler J, Piwowarska W. Lyme carditis: epidemiology, pathophysiology, and clinical features in endemic areas. Int J Cardiol 2010,144:328-333.

58. Bateman H, Sigal L. Update on Lyme Carditis. Curr Infect Dis Rep 2000,2:299-301.

59. Kostic T, Momcilovic S, Perisic ZD, Apostolovic SR, Cvetkovic J, Jovanovic A, et al. Manifestations of Lyme carditis. Int J Cardiol 2017,232:24-32.

60. Forrester JD, Mead P. Third-degree heart block associated with lyme carditis: review of published cases. Clin Infect Dis 2014,59:996-1000.

61. van der Linde MR. Lyme carditis: clinical characteristics of 105 cases. Scand J Infect Dis Supp/ 1991,77:81-84.

62. Mahne J, Kranjc BS, Strle F, Ruzic-Sabljic E, Arnez M. Panuveitis caused by Borrelia burgdorferi sensu lato infection. Pediatr Infect Dis J 2015,34:102-104.

63. Wallet F, Labalette P, Herwegh S, Loiez C, Margaron F, Courcol R. Molecular diagnosis of a bilateral panuveitis due to Borrelia burgdorferi sensu lato by cerebral spinal fluid analysis. Jpn J Infect Dis 2008,61:214-215.

64. Dietrich T, Geissdorfer W, Schlotzer-Schrehardt U, Holbach L, Schoerner C, Seitz B. Borrelia-associated crystalline keratopathy with intracorneal detection of Borrelia garinii by electron microscopy and polymerase chain reaction. Cornea 2008,27:498-500.

65. Croskerry P. From mindless to mindful practice--cognitive bias and clinical decision making. N Eng/ J Med 2013,368:2445-2448.

66. Haddad E, Chabane K, Jaureguiberry S, Monsel G, Pourcher V, Caumes E. Holistic approach in patients with presumed Lyme borreliosis leads to less than $10 \%$ of confirmation and more than $80 \%$ of antibiotics failure. Clin Infect Dis 2018. 
Figure 1. Les différentes stases d'Ixodes ricinus.

Source : N. Boulanger
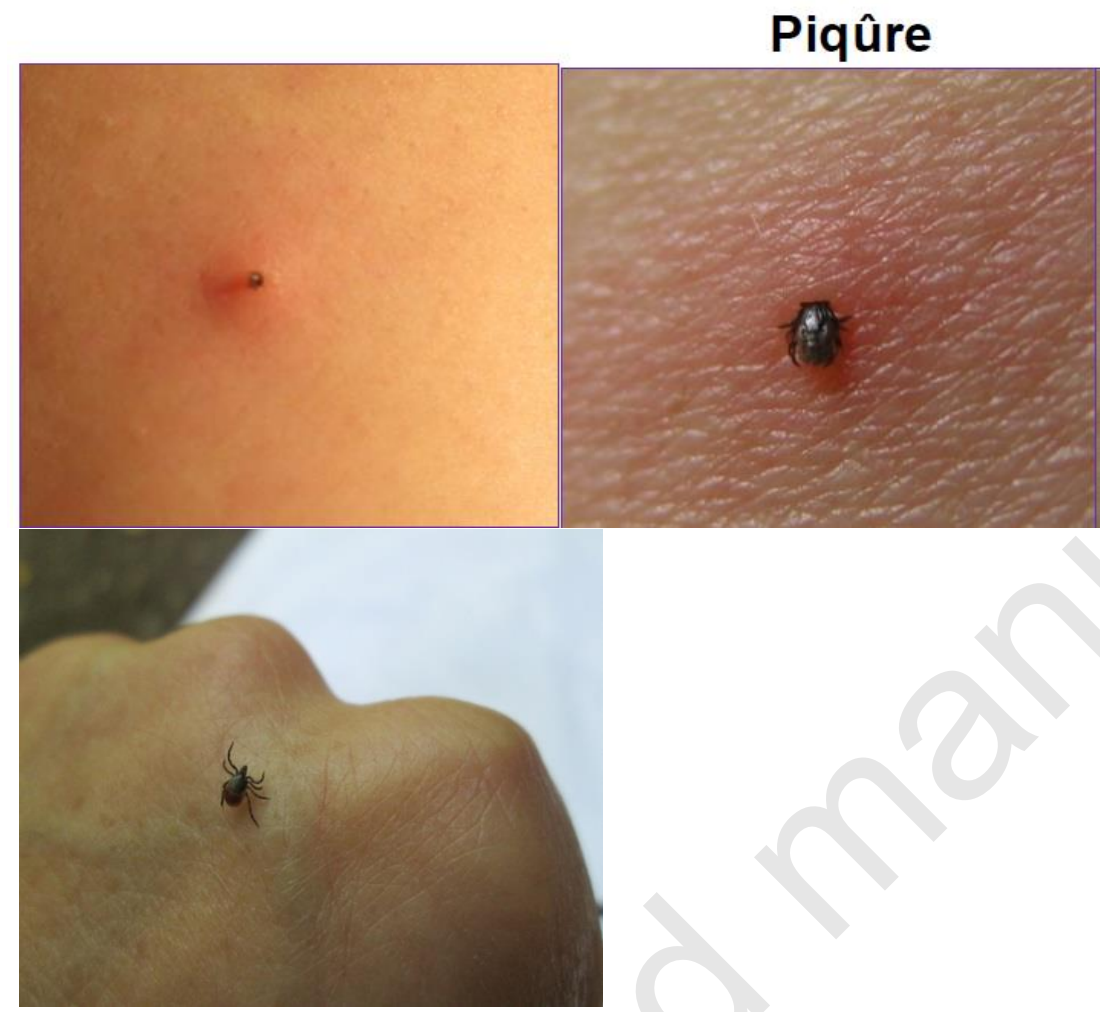

1.a : larve

1.b : nymphe

1.c : adulte femelle

Figure 2. Exemples de réaction inflammatoire cutanée après piqûre de tique.

Source : N. Boulanger

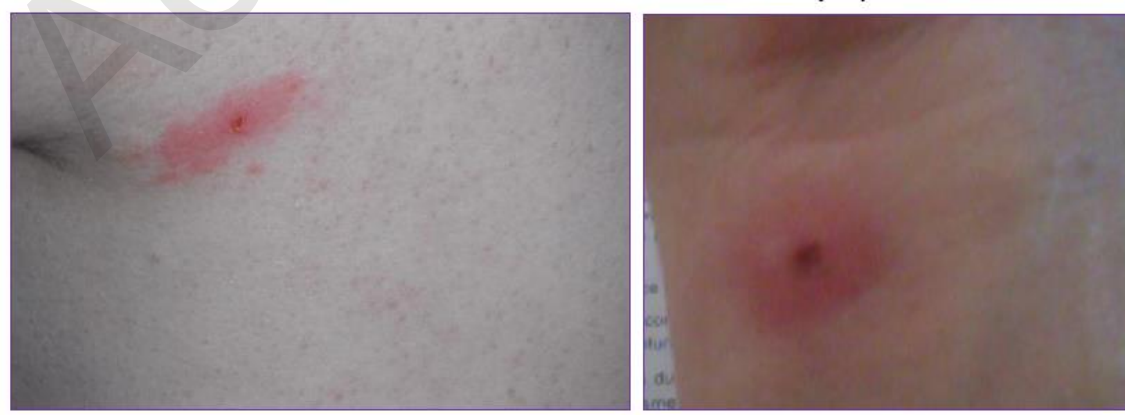

Réaction à la salive

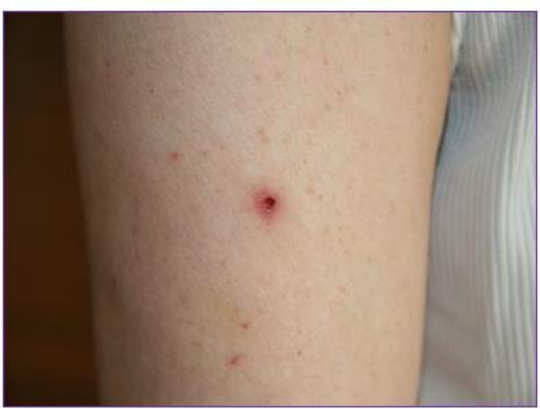

Nécrose 
Figure 3. Estimation de l'incidence de la Borréliose de Lyme par région, 2013 - 2017, France métropolitaine

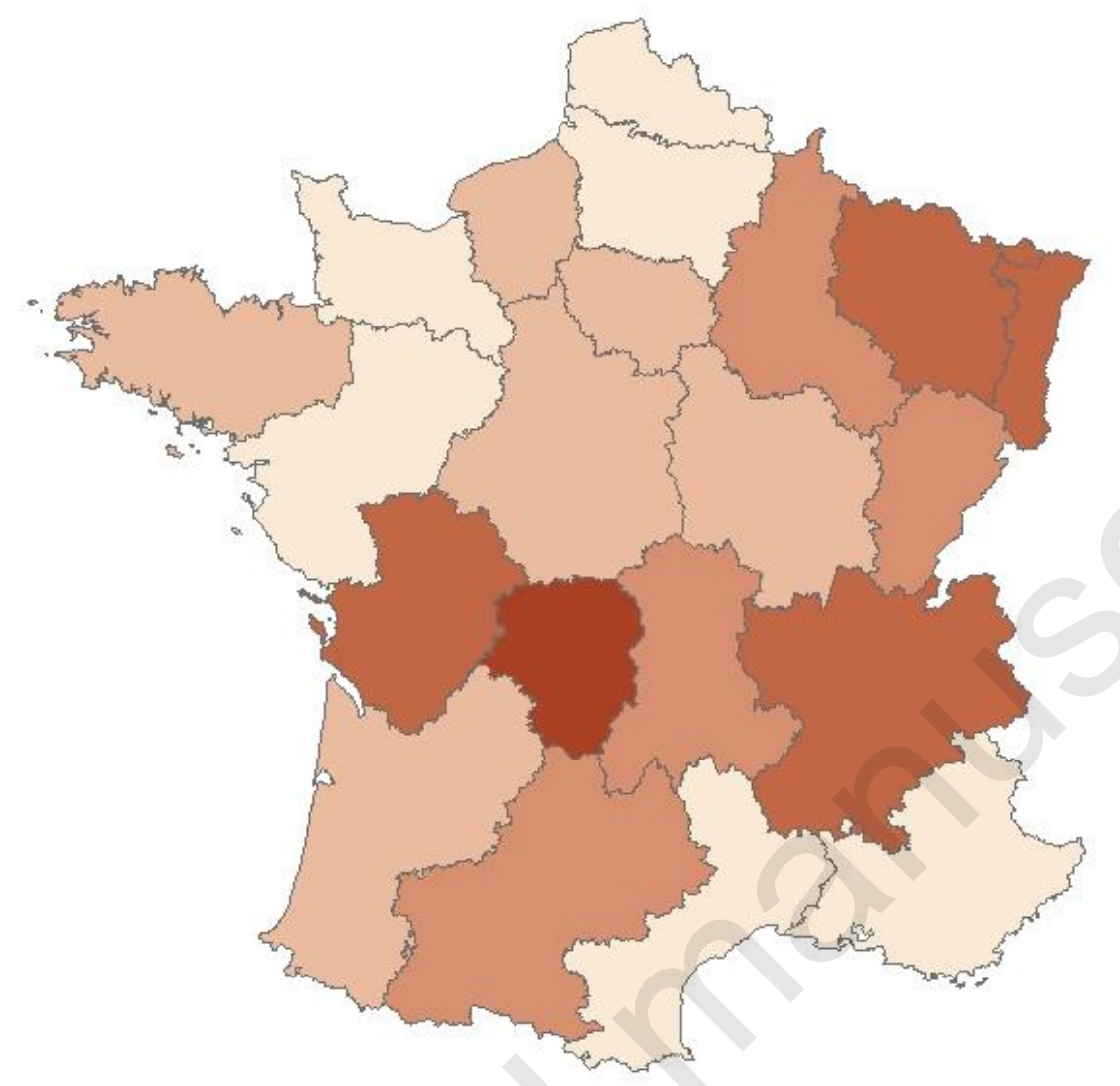

\section{Incidence pour 100000 habitants}
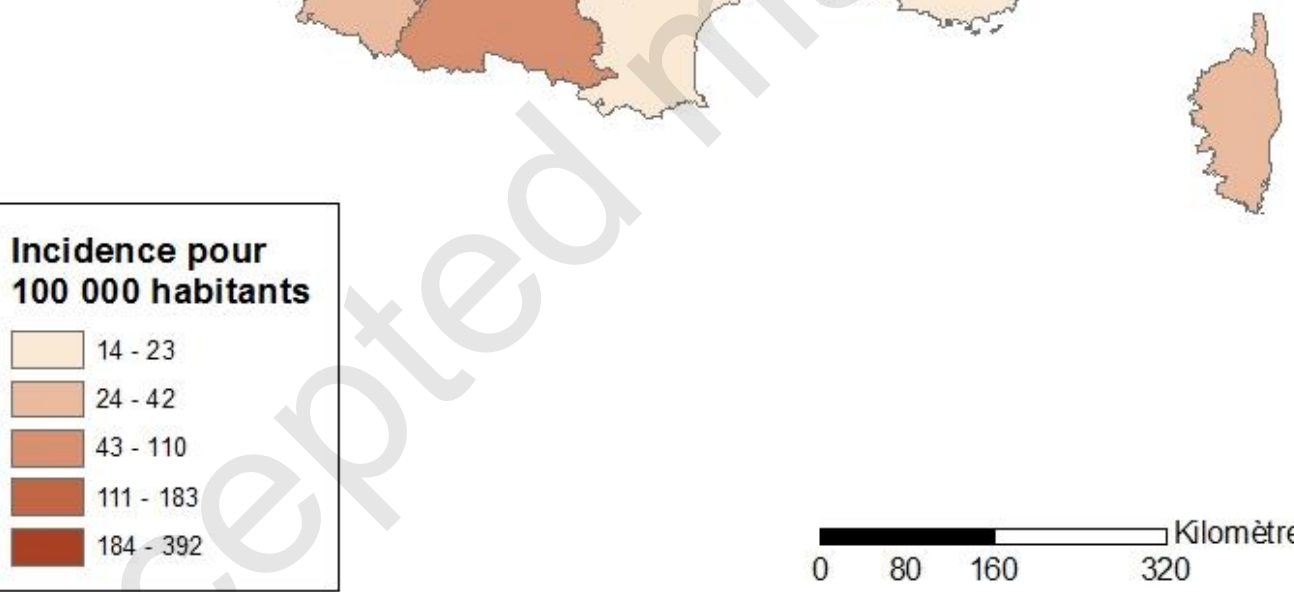

Source : Sante publique France, d'après les données du Réseau Sentinelles, 2019 
Figure 4. Histoire de la maladie et tests diagnostiques

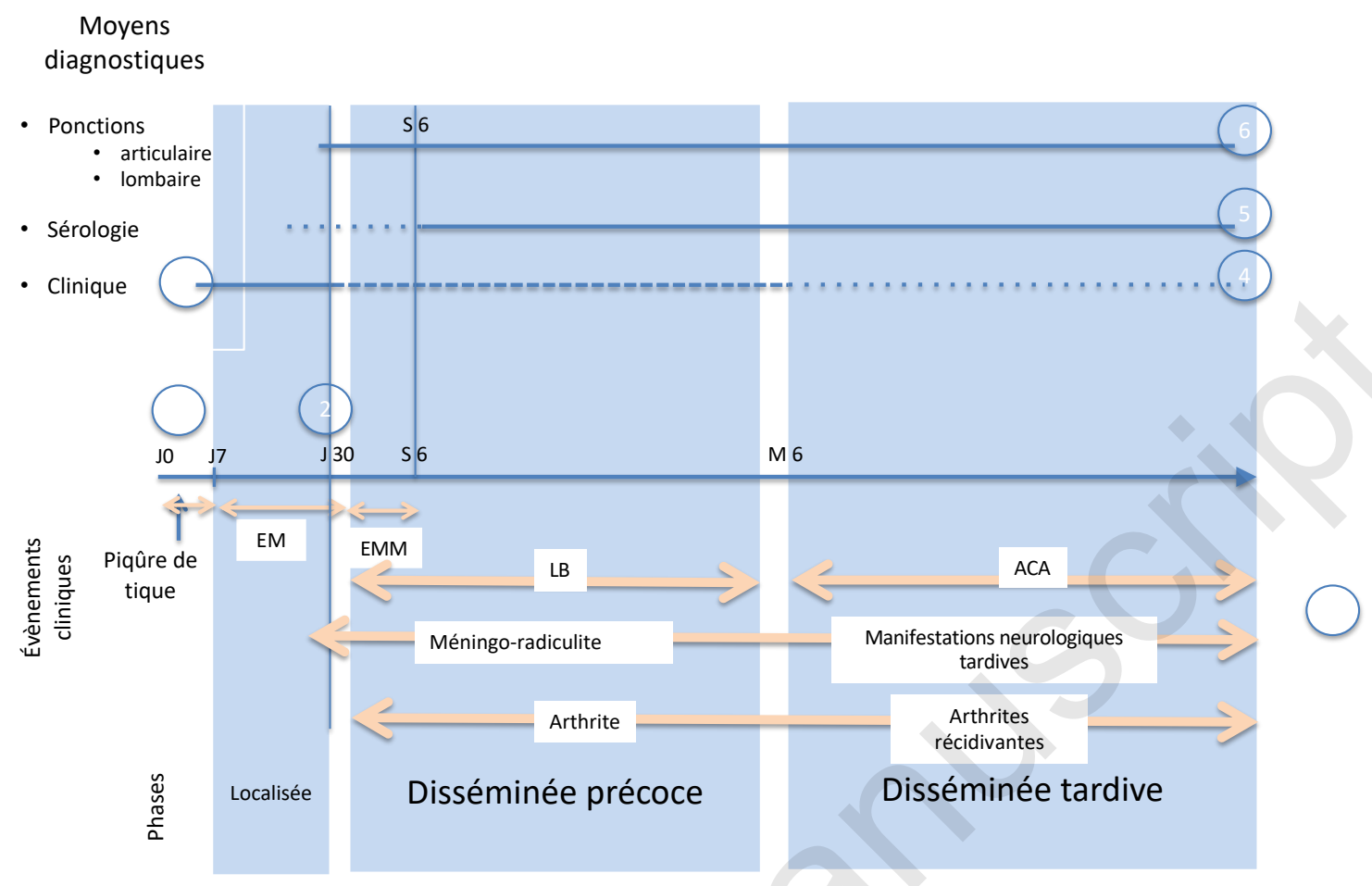

Notes : EM, érythème migrant ; EMM, érythème migrant multiple ; LB, lymphocytome borrélien; ACA, acrodermatite chronique atrophiante.

La piqûre de tique peut durer 4 à 7 jours selon le stade de la tique

L'érythème migrant peut encore être présent au début de la méningoradiculite

Le diagnostic repose uniquement sur la clinique à la phase précoce

Les signes cliniques sont moins spécifiques lors des phases disséminées et surtout tardives

La sérologie peut être négative dans les phases précoces, mais sa sensibilité devient satisfaisante à partir de la $6^{\text {ème }}$ semaine Pour les phases tardives, la sérologie a une excellente valeur prédictive négative

L'identification de Borrelia dans le liquide articulaire voire le liquide cérébrospinal et la présence d'une réaction méningée associée à une synthèse intrathécale d'Ac spécifques affirment le diagnostic

Dans 50 à $75 \%$ des cas, les formes disséminées ne sont pas précédés d'un érythème migrant et la piqûre de tique peut être oubliée ou être passée inaperçue 
Figure 5. Algorithme diagnostique pour les manifestations articulaires des borrélioses

Mono ou oligoarthrite des grosses articulations

Rechercher à l'interrogatoire et à l'examen clinique

- une porte d'entrée notamment cutanée

une notion d'exposition aux tiques, une piqûre

de tique ou un érythème migrant

Des signes généraux comme la fièvre

des signes extra-articulaires : uvéite, $\mathrm{MICl}$,

psoriasis, atteintes dites axiales (lombalgies

inflammatoires, douleur thoracique

inflammatoire), atteintes enthésitiques (tendon

d'Achille, tendon rotulien...) ou autres signes

évocateurs de pathologies inflammatoires

rhumatismales, microcristallines ou auto-

immunes

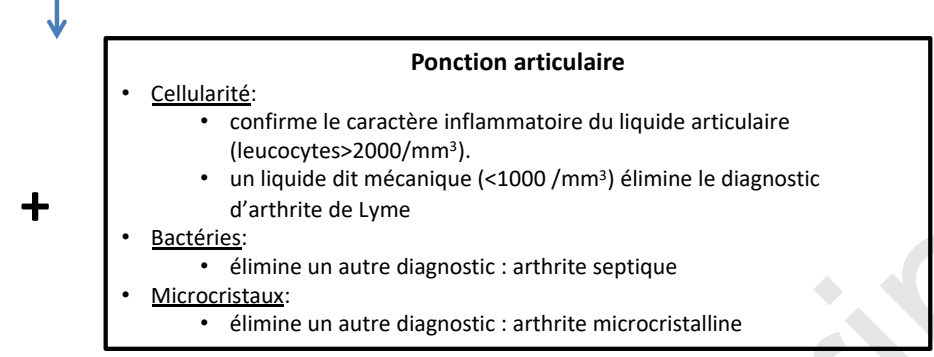

En l'absence d'autre diagnostic et devant un contexte évocateur

\begin{tabular}{|l|}
\hline sérologie de Lyme sanguine. \\
négative \\
Diagnostic d'arthrite de \\
Lyme éliminé
\end{tabular}

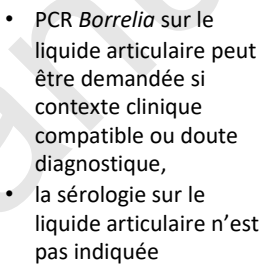


Tableau 2. Principaux diagnostics différentiels des formes cutanées de la borréliose de Lyme

\begin{tabular}{|c|c|}
\hline \multicolumn{2}{|l|}{ Erythème migrant } \\
\hline Diagnostic différentiel & Eléments distinctifs \\
\hline Réaction à la piqûre d'arthropode & $\begin{array}{l}\text { Lésion présente immédiatement après la piqûre, } \\
\text { prurit, absence d'extension progressive }\end{array}$ \\
\hline Urticaire & Migration en moins de $12-24 \mathrm{~h}$, prurit, œdème \\
\hline Granulome annulaire & $\begin{array}{l}\text { Lésions infiltrées par endroits, extension non } \\
\text { régulière et lente, aspect histologique spécifique }\end{array}$ \\
\hline Erythème pigmenté fixe & $\begin{array}{l}\text { Contexte de prise médicamenteuse, absence } \\
\text { d'extension des lésions }\end{array}$ \\
\hline Morphée & $\begin{array}{l}\text { Atrophie cutanée (formes superficielles), induration } \\
\text { (formes classiques), absence d'extension régulière, } \\
\text { aspect histologique spécifique }\end{array}$ \\
\hline Dermatophytose & $\begin{array}{l}\text { Bordure vésiculeuse, squameuse ou croûteuse, prurit } \\
\text { important, prélèvement mycologique de squame } \\
\text { positif }\end{array}$ \\
\hline \multicolumn{2}{|l|}{ Lymphocytome borrélien } \\
\hline Diagnostic différentiel & Eléments distinctifs \\
\hline Pseudo-lymphome non borrélien & $\begin{array}{l}\text { Contexte particulier (médicament, tatouage...), } \\
\text { sérologie Borrelia négative, absence de régression } \\
\text { sous traitement }\end{array}$ \\
\hline Sarcoïdose & $\begin{array}{l}\text { Caractère lupoïde à la vitropression, aspect } \\
\text { histologique spécifique }\end{array}$ \\
\hline Lymphome B cutané primitif & $\begin{array}{l}\text { Aspect histologique spécifique (attention : un } \\
\text { lymphocytome borrélien peut parfois mimer } \\
\text { histologiquement un lymphome) }\end{array}$ \\
\hline \multicolumn{2}{|c|}{ Acrodermatite chronique atrophiante } \\
\hline Diagnostic différentiel & Eléments distinctifs \\
\hline $\begin{array}{l}\text { Insuffisance veineuse chronique } \\
\text { (dermite de stase) }\end{array}$ & $\begin{array}{l}\text { Anomalies du bilan angiologique, poussées } \\
\text { inflammatoires récurrentes avec prurit et eczéma, } \\
\text { dermite ocre, absence d'atrophie }\end{array}$ \\
\hline $\begin{array}{l}\text { Acrosyndromes (acrocyanose, } \\
\text { érythermalgie) }\end{array}$ & $\begin{array}{l}\text { Caractère bilatéral, souvent paroxystique rythmé par } \\
\text { la température ambiante, absence d'atrophie }\end{array}$ \\
\hline $\begin{array}{l}\text { Syndrome douloureux régional } \\
\text { complexe }\end{array}$ & $\begin{array}{l}\text { Contexte de traumatisme ou intervention chirurgicale } \\
\text { troubles vasomoteurs, hyperhidrose, absence } \\
\text { d'atrophie }\end{array}$ \\
\hline
\end{tabular}


Tableau 3 : Examens complémentaires utiles pour le diagnostic différentiel des neuroborrélioses

\begin{tabular}{|c|c|c|c|}
\hline Situation clinique & $\begin{array}{c}\text { Examens } \\
\text { complémentaires }\end{array}$ & $\begin{array}{c}\text { Signes dans les } \\
\text { neuroborrélioses }\end{array}$ & Diagnostic différentiel \\
\hline Méningo-radiculite & $\begin{array}{c}\text { IRM médullaire } \\
\text { Ponction lombaire }\end{array}$ & $\begin{array}{l}\text { Prise de contraste } \\
\text { radiculaire, ou } \\
\text { leptoméningée }\end{array}$ & $\begin{array}{c}\text { Compression de } \\
\text { racine(s) nerveuse(s), } \\
\text { méningo-radiculite due } \\
\text { à d'autres germes }\end{array}$ \\
\hline Polyneuropathie & EMG & $\begin{array}{l}\text { Jamais une } \\
\text { polyneuropathie } \\
\text { symétrique } \\
\text { distale longueur- } \\
\text { dépendante }\end{array}$ & $\begin{array}{c}\text { Autres causes plus } \\
\text { fréquentes de } \\
\text { polyneuropathie }\end{array}$ \\
\hline $\begin{array}{l}\text { Encéphalites aiguës ou } \\
\text { subaiguës }\end{array}$ & $\begin{array}{c}\text { IRM cérébrale } \\
\text { Ponction lombaire }\end{array}$ & $\begin{array}{c}\text { Index anticorps } \\
\text { LCS/sérum }\end{array}$ & $\begin{array}{c}\text { Encéphalite herpétique, } \\
\text { encéphalite à tiques }\end{array}$ \\
\hline $\begin{array}{l}\text { Atteintes cérébro- } \\
\text { vasculaires }\end{array}$ & $\begin{array}{l}\text { TDM ou IRM } \\
\text { cérébrale }\end{array}$ & $\begin{array}{l}\text { infarctus } \\
\text { cérébraux } \\
\text { lacunaires }\end{array}$ & $\begin{array}{l}\text { Accident vasculaire } \\
\text { cérébral athéromateux } \\
\text { ou cardio-embolique. }\end{array}$ \\
\hline $\begin{array}{l}\text { Encéphalopathie } \\
\text { chronique }\end{array}$ & $\begin{array}{l}\text { Evaluation cognitive } \\
\text { IRM cérébrale } \\
\text { Ponction lombaire }\end{array}$ & 8 & $\begin{array}{l}\text { Démence dégénérative } \\
\text { et troubles apparentés }\end{array}$ \\
\hline
\end{tabular}

IRM, imagerie par résonance magnétique ; EMG, électromyogramme ; TDM, tomodensitométrie

\section{Critères européens du diagnostic de neuroborréliose de Lyme:}

1. Symptômes compatibles avec une neuroborréliose non expliqués par ailleurs

2. Pléiocytose du liquide cérébro-spinal

3. Index anticorps témoignant d'une synthèse intrathécale d'anticorps anti-Borrrelia 
Tableau 4. Bilan cardiaque d'une borréliose de Lyme : quand, comment ?

Un bilan cardiaque est envisagé soit en raison de symptômes (palpitations, syncope, douleurs thoraciques, dyspnée), soit pour déceler une atteinte infraclinique.

\begin{tabular}{|c|c|c|}
\hline Recommandation & Classe & Niveau de preuve \\
\hline $\begin{array}{l}\text { Des symptômes cardiaques (douleur thoracique, dyspnée, } \\
\text { palpitation, syncope) sont recherchés à l'interrogatoire } \\
\text { d'un patient atteint de borréliose de Lyme }\end{array}$ & $\mathrm{I}$ & B \\
\hline $\begin{array}{l}\text { En présence de symptômes cardiaques, un bilan cardiaque } \\
\text { orienté par le type de symptômes est réalisé }\end{array}$ & I & B \\
\hline $\begin{array}{l}\text { La présence de modifications ECG ou d'élévation de la } \\
\text { troponine nécessite un avis et un suivi cardiologique }\end{array}$ & I & $\mathrm{C}$ \\
\hline $\begin{array}{l}\text { Un Holter ECG est enregistré chez les malades présentant } \\
\text { un bloc auriculo-ventriculaire du premier ou second degré, } \\
\text { ou des troubles rythmiques supra-ventriculaires ou } \\
\text { ventriculaires }\end{array}$ & $\mathrm{I}$ & $\mathrm{C}$ \\
\hline $\begin{array}{l}\text { Les patients ayant un bloc auriculo-ventriculaire du } 2^{\mathrm{e}} \text { ou } \\
3^{\mathrm{e}} \text { degré, un intervalle } \mathrm{PR} \geq 300 \mathrm{~ms} \text {, ou une dysfonction } \\
\text { ventriculaire gauche sont hospitalisés avec monitorage } \\
\text { ECG }\end{array}$ & I & $\mathrm{C}$ \\
\hline $\begin{array}{l}\text { L'indication de la stimulation cardiaque temporaire ou } \\
\text { définitive est portée en fonction de la sévérité du bloc } \\
\text { auriculo-ventriculaire et de son évolution sous traitement } \\
\text { antibiotique }\end{array}$ & & $\mathrm{C}$ \\
\hline
\end{tabular}


Tableau 5. Stratégie de prise en charge en cas de symptômes débutant dans les 4 semaines suivant une piqure de tique en France

- Toutes les infections transmises par les tiques peuvent se manifester par une fièvre isolée

- Des symptômes moins spécifiques sont souvent associés à la fièvre: myalgies, courbatures, troubles digestifs. Ils peuvent être présents chez la plupart des patients fébriles et ne constituent pas dans ce contexte des signes orientant vers une cause plus précise

- La fatigue/asthénie est souvent retrouvée dans les présentations cliniques décrites, néanmoins, sans aucun autre signe objectif associé, elle n'est pas évocatrice d'une maladie transmise par les tiques

\begin{tabular}{|c|c|c|c|c|c|}
\hline $\begin{array}{l}\text { Présentation } \\
\text { clinique }\end{array}$ & $\begin{array}{l}\text { Pathologies à } \\
\text { évoquer }\end{array}$ & $\begin{array}{l}\text { Exposition/éléments } \\
\text { clinique }\end{array}$ & $\begin{array}{l}\text { Eléments } \\
\text { biologiques }\end{array}$ & Stratégie diagnostique & $\begin{array}{l}\text { Traitement à } \\
\text { envisager }\end{array}$ \\
\hline $\begin{array}{l}\text { Fièvre + } \\
\text { signes méningés OU } \\
\text { encéphalitiques }\end{array}$ & TBE & $\begin{array}{l}\text { Est de la France, Savoie, } \\
\text { (voyageur zone d'endémie) }\end{array}$ & $\begin{array}{l}\text { Méningite } \\
\text { lymphocytaire }\end{array}$ & Sérologie IgM et lgG sérum et LCS & symptomatique \\
\hline \multirow{3}{*}{$\begin{array}{l}\text { Fièvre }+ \\
\text { Adénopathie }+ \\
\text { Escarre d'inoculation }\end{array}$} & Tularémie & & & $\begin{array}{l}\text { PCR/culture pus ganglionnaire; } \\
\text { écouvillon escarre ; Sérologie }\end{array}$ & $\begin{array}{l}\text { Ciprofloxacine } \\
\text { ou Doxycycline }\end{array}$ \\
\hline & Senlat/Tibola & Localisation cuir chevelu & & \multirow{2}{*}{$\begin{array}{l}\text { PCR écouvillon d'escarre, PCR } \\
\text { ponction ganglionnaire, Sérologie }\end{array}$} & Doxycycline \\
\hline & LAR & $\begin{array}{l}\text { Trainée de lymphangite +/- } \\
\text { éruption maculo-papuleuse }\end{array}$ & & & Doxycycline \\
\hline $\begin{array}{l}\text { Fièvre + } \\
\text { splénomégalie }\end{array}$ & Babésiose & & & Frottis sanguin, PCR & $\begin{array}{l}\text { Association ATB } \\
+ \text { ATP } 1\end{array}$ \\
\hline \multirow[t]{2}{*}{$\begin{array}{l}\text { Fièvre + éruption } \\
\text { maculo papuleuse }\end{array}$} & Rickettsioses & $\begin{array}{l}\text { Bassin méditerranéen, } \\
\text { localisation palmo-plantaire }\end{array}$ & Cytopénies & $\begin{array}{l}\text { PCR ponction ganglionnaire, } \\
\text { Sérologie }\end{array}$ & Doxycycline \\
\hline & Anaplasmose & & $\begin{array}{l}\text { Cytopénies + } \\
\text { Lymphocytes activés } \\
+ \text { Cytolyse hépatique }\end{array}$ & PCR sanguine, sérologie & Doxycycline \\
\hline \multirow[t]{3}{*}{$\begin{array}{l}\text { Ulcération cutanée } \\
\text { avec ou sans fièvre }\end{array}$} & FBM & Bassin méditerranéen & Cytopénies & $\begin{array}{l}\text { PCR écouvillon d'escarre, PCR } \\
\text { ponction ganglionnaire, Sérologie }\end{array}$ & Doxycycline \\
\hline & Tularémie & & & $\begin{array}{l}\text { PCR/culture pus ganglionnaire; } \\
\text { écouvillon escarre ; Sérologie }\end{array}$ & $\begin{array}{l}\text { Ciprofloxacine } \\
\text { OU Doxycycline }\end{array}$ \\
\hline & $\begin{array}{l}\text { TIBOLA, } \\
\text { SENLAT }\end{array}$ & Cuir chevelu & & $\begin{array}{l}\text { PCR écouvillon d'escarre, PCR } \\
\text { ponction ganglionnaire, Sérologie }\end{array}$ & Doxycycline \\
\hline
\end{tabular}

$1:$ Traitement après avis spécialisé d'infectiologie $;$ TBE $=$ Encéphalite à tique ; FBM = Fièvre Boutonneuse Méditerranéenne ; ATB $=$ antibiotique ; ATP $=$ antiparasitaire SENLAT = Scalp Eschar associated with Neck Lymphadenopathy after Tick bite ; TIBOLA = Tick-Borne LymphAdenitis ; LAR = Lymphangitis associated Rickettsia 